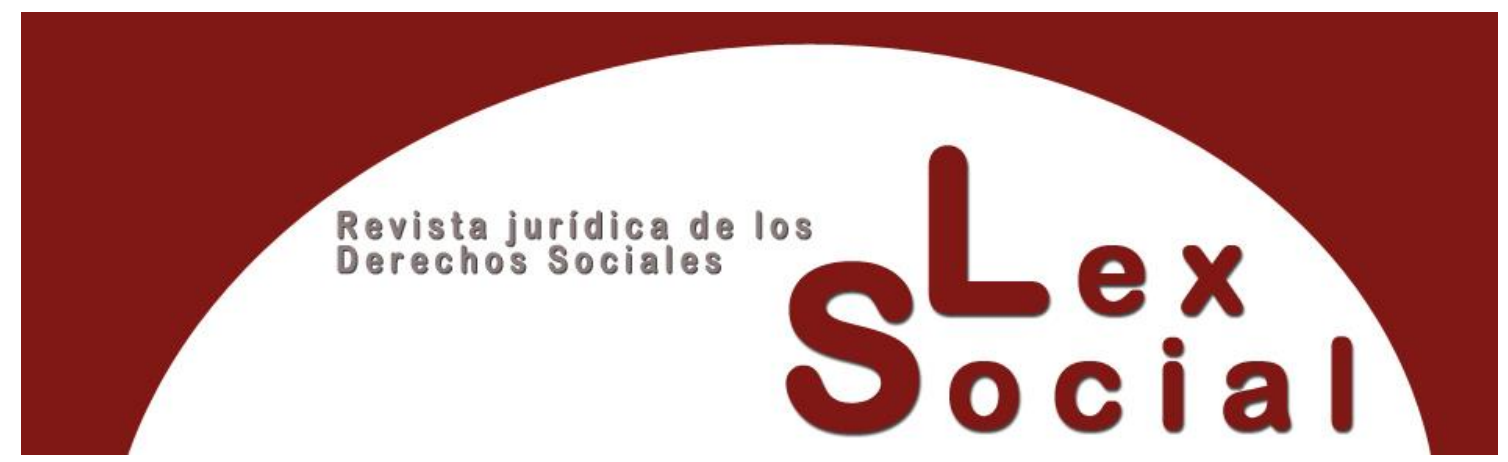

\title{
DE LA CONCILIACIÓN A LA CORRESPONSABILIDAD EN EL TIEMPO DE TRABAJO: UN CAMBIO DE PARADIGMA IMPRESCINDIBLE PARA CONSEGUIR EL TRABAJO DECENTE ${ }^{1}$ \\ FROM CONCILIATION TO WORKING TIME CO-RESPONSIBILITY: AN ESSENTIAL PARADIGM SHIFT TO ACHIEVE DECENT WORK
}

\author{
EMMA RODRÍGUEZ RODRÍGUEZ \\ Profesora Contratada Doctora (Titular Acreditada) \\ de Derecho del Trabajo y de la Seguridad Social \\ Universidad de Vigo \\ https://orcid.org/0000-0002-0770-0195
}

Cómo citar este trabajo: Rodríguez Rodríguez, E. (2021). De la conciliación a la corresponsabilidad en el tiempo de trabajo: un cambio de paradigma imprescindible para conseguir el trabajo decente. Lex Social: Revista De Derechos Sociales, 11(1), 40-78 https://doi.org/10.46661/lexsocial.5470

\section{RESUMEN}

Las labores de cuidado no tienen género, sin embargo, su tradicional vinculación al femenino ha supuesto un lastre para la plena integración de las mujeres en el mundo laboral. Ante la digitalización de la economía, las TICs y el teletrabajo se han revelado como nuevas formas de segregación ocupacional, en lugar de suponer un avance hacia la igualdad de oportunidades, tal y como se concebían en su origen. Las anticuadas fórmulas vinculadas a la reducción del tiempo de trabajo sólo han ahondado en la desprofesionalización de quien las asume. La crisis sanitaria motivada por el COVID-19 ha visibilizado la magnitud de las labores de cuidado. La OIT, a través de los ODS y de la proclamación del trabajo decente, así como la Unión Europea vienen requiriendo a los Estados miembro para que intervengan activamente en pro de la corresponsabilidad, más allá de la conciliación de la vida

\footnotetext{
${ }^{1}$ Este trabajo se inscribe en el marco del Proyecto de Investigación "Los derechos fundamentales ante el cambio del trabajo autónomo en la era digital", DER2017-83488-C4-2-R, del Ministerio de Ciencia, Innovación y Universidades.
} 
familiar y laboral de cada persona trabajadora. El trabajo decente será corresponsable o no será.

Palabras Clave: conciliación, corresponsabilidad, tiempo de trabajo, trabajo decente, cuidados.

\begin{abstract}
Care work is gender-neutral, but traditionally its linkage to the female gender has ballasted the full integration of women into the labour market. Given the digitalization of the economy, ICTs and the use of teleworking have revealed themselves as new forms of occupational segregation, instead of representing progress towards equal opportunities, as they were originally conceived. The outdated formulas linked to the reduction of working time have only deepened the de-professionalisation of those who take them on. The health crisis caused by the COVID-19 has yielded care work. The ILO, through the sustainable development goals and the proclamation of decent work, as well as the European Union have urged member States to actively claim for co-responsibility, beyond work-life balance. Decent work will either be co-responsible or not.
\end{abstract}

KEYWORDS: reconciliation, co-responsibility, working time, decent work, care.

SUMARIO

I. El empoderamiento de la persona trabajadora sobre el reparto de sus tiempos vitales. II. Las medidas para favorecer la conciliación laboral frente al impacto social y económico del COVID-19.

1. El carácter preferente del trabajo a distancia.

2.- El Plan MECUIDA: adaptación y reducción de jornada.

III. El teletrabajo y los derechos de conciliación de calidad.

IV. La disfuncionalidad del trabajo a tiempo parcial como medida de conciliación.

$V$. Reflexiones finales: el reconocimiento del trabajo de los cuidados.

Bibliografía

\title{
I. El empoderamiento de la persona trabajadora sobre el reparto de sus tiempos vitales
}

People care about the future of our children and our society, and about fairness and equality in every sense of the word, son las palabras de la Presidenta Ursula von der Leyen 
con las que comenzó la Comunicación de la Comisión sobre "una Europa social más fuerte para una justa transición"2.

En efecto, el año 2019 fue un año de esperanza y de buenos propósito para todo lo que se refería a los derechos sociales. La mejoría en las perspectivas económicas permitió, por fin, relajar las normativas nacionales, centradas en mecanismos de flexibilidad empresarial y contención del défit, para pasar a fijarse en unos nuevos trabajadores "atípicos" y "precarios" a los que urge dotar de derechos frente a sus empresas plataformas digitales, fundamentalmente- que les negaban esa condición de empleados.

Tanto es así que la Declaración del Centenario de la OIT para el Futuro del Trabajo, adoptada en la Conferencia 108 , celebrada el 21 de junio, en Ginebra, se refirió a un "enfoque del futuro del trabajo centrado en las personas", hacia el trabajo "que queremos". Lo cierto es que, meses antes, la Comisión mundial de la OIT, en su informe "trabajar para un futuro prometedor", del 22 de enero, destacó que "la Constitución de la OIT sigue siendo el contrato social más ambicioso de la historia" e interpeló a su revitalización, en el marco de la Agenda Global de la ONU 2030 y los Objetivos de Desarrollo del Milenio -justicia social, el pleno empleo, el fin de la pobreza, la igualdad de género y la reducción de las desigualdades...-

Uno de los ejes sobre el que gira el objetivo genérico de la universalización de un "trabajo decente y sostenible" es la igualdad de género, por su capacidad de integración de la diversidad $^{3}$. Es por ello que la igualdad real entre los géneros se impone como una base de la que partir y formular unas líneas generales que sustenten el reparto igualitario de los tiempos de cuidado o de vida personal y de los tiempos de trabajo o profesionales. Ciertamente es histórica la reinvidincación sobre la distribución equitativa y diferenciada de ambos espacios temporales para que el tiempo remunerado no resulte más importante que el restante.

La Comisión llamó la atención, en concreto, sobre la "mayor soberanía" de las personas trabajadores respecto de su el tiempo de trabajo como una herramienta básica para avanzar hacia su bienestar, sus derechos de conciliación y, en consecuencia, hacia la igualdad por razón de género. Según la Comisión, el instrumento jurídico o el procedimiento más adecuado para conseguirlo será el diálogo social, con la implicación tripartita de los organismos más interesados, los interlocutores sociales -empresarios y trabajadores-, pero también el gobierno o el Estado, como responsable último de dar cumplimiento al mandato constitucional.

En definitiva, el "empoderamiento" de los trabajadores en torno al reparto de sus tiempos vitales, se propugna desde la Comisión mundial como un cambio de paradigma fundamental para conseguir el "trabajo decente". De hecho, el modelo clásico sobre el

\footnotetext{
${ }^{2}$ Communication from the Commission to the European Parliament, the Council, the European Economic and Social Committee and the Committee of the Regions "A strong social Europe for just transitions". Brussels, 14.1.2020. COM (2020) 14 final.

3 Análisis sobre estos documentos, CASAS BAAMONDE, M". Emilia, "La organización del tiempo de trabajo con perspectiva de género: ña conciliación de la vida privada y la vida laboral", Documentación Laboral, $\mathrm{n}^{\circ} .117,2019$, pp. 18-21.
} 
que se asientan las normas tradicionales del ordenamiento jurídico como punto de partida -jornada ordinaria a tiempo completo- no resultan válidas ahora, en una organización del trabajo mucho más variable, imprevisible y que utiliza el tiempo de trabajo como un derecho "adaptativo" para el trabajador, especialmente en los trabajos de menos calidad, muchas veces desempeñados por mujeres y jóvenes.

Frente a esta desregularización, Declaración del Centenario de la OIT para el Futuro del Trabajo se refiere al establecimiento de límites máximos genéricos a las jornadas laborales, dentro de las "circunstancias nacionales", y se remite para su concreción a los acuerdos entre trabajadores y empresarios. Resulta decepcionante4 que no se muestre más incisiva, como propuso la Comisión mundial, que reclamaba el establecimiento de un "límite mínimo de horas de trabajo garantizadas y previsibles que genere opciones reales de flexibilidad y control sobre los horarios de trabajo". El día 11 de marzo, la Oficina Internacional del Trabajo hizo público el Informe de la Comisión de Expertos en Aplicación de Convenios y Recomendaciones, relativo a puntos estratégicos para la próxima Conferencia Internacional del Trabajo, que estaba prevista del 25 de mayo al 5 de junio ${ }^{5}$, en el que se refiere a la igualdad de género y a la no discriminación como cuestiones transversales en cada uno de los cuatro objetivos estratégicos en los que pretende incidir para garantizar empleos con derechos sociales básicos y trabajo decente.

Como es sabido, en la Unión Europea, el balance vida-trabajo ha sido un tema central y consustancial a su propia evolución normativa, convirtiéndose en la punta de lanza del derecho a la igualdad de género ${ }^{6}$. Clara muestra de esto ha sido el impulso recogido sobre todo en los borradores iniciales- en el Pilar Europeo de Derechos Sociales ${ }^{7}$, heredero de las múltiples Directivas en el mismo sentido, pero también de los derechos reconocidos ad initio en la Carta Social Europea y en su versión revisada, con lo que implica su ratificación en cuanto a derechos sociales ${ }^{8}$. De hecho, el 24 de marzo de 2020 se publicaron las Conclusiones del Comité Europeo de Derechos Sociales correspondientes al año 2019/XXI-4, relativas a los derechos de los menores, de las familias migrantes, aunque amplía su análisis final a la protección social de todos frente a la pobreza y exclusión social derivada de la pandemia ${ }^{9}$. Del estudio de los resultados sobre los mecanismos de supervisión, por lo que aquí se refiere, destacan aquellos que comprometen a las partes a establecer medidas para promover el acceso efectivo entre

\footnotetext{
${ }^{4}$ Ibídem.

${ }^{5}$ https://www.ilo.org/wcmsp5/groups/public/---ed_norm/--relconf/documents/meetingdocument/wcms 670148.pdf .

${ }^{6}$ BITTMAN Michael y FOLBRE, Nancy, Family time. The social organization of care, Ed. Routledge, London-New Yok, 2004, pp. 1-4.

${ }^{7}$ RAMOS QUINTANA, Margarita I., "El Pilar Europeo de Derechos Sociales: la nueva dimensión social europea", Revista de Derecho Social, $\mathrm{n}^{\circ}$. 77, 2017, pp.19-42.

${ }^{8}$ Hay que recordar que, en el Proceso de Turín I, desarrollado los días 17 y 18 de octubre, fue proclama oficialmente como la "Constitución Social Europea", como ya venía llamando la atención sobre su importancia la magnífica obra de SALCEDO BELTRÁN, Carmen, "La Carta Social Europea y la protección de los Derechos Sociales en el marco del Consejo de Europa", en AA.VV., Lecciones sobre Estado Social y Derechos Sociales, Tirant lo Blanch, Valencia, 2014, pp. 154-162.

${ }^{9} \mathrm{Al}$ respecto, un estudio pormenorizado, SALCEDO BELTRÁN, Carmen, "La crítica situación de los derechos sociales de la infancia, de las familias y de los migrantes: Conclusiones 2019 del Comité Europeo de Derechos Sociales", Revista de Derecho de las Relaciones Laborales, $\mathrm{n}^{\circ}$. 6, junio 2020, pp. 900-917.
} 
otros bienes, al empleo, a la vivienda, a la formación, de personas o familias que se encuentren o corran el riesgo de encontrarse en una situación de exclusión social o de pobreza (art.30). Este precepto general sobre la protección social conecta con el derecho a la igualdad de oportunidades en el empleo, como desafío principal para reducir la feminización de la pobreza (art. 20), así como con las garantías hacia la protección del embarazo y la maternidad (art. 8, apartados 4 y 5), a través de mecanismos jurídicos que prohíban la discriminación retributiva y faciliten la adaptación y flexibilidad de los puestos y horarios de trabajo, eliminando cualquier tipo de discriminación por razón de sexo.

Tradicionalmente, entre las instituciones que permiten conciliar la vida personal y la laboral se señalan, en primer lugar, a los permisos, en sentido amplio, que permitan a las personas trabajadoras interrumpir sus carreras profesionales para dedicarse al cuidado de sus familiares. Asimismo, cada vez se ha hecho más hincapié en que deben de procurarse horarios de trabajo flexibles, para posibilitar que las condiciones laborables puedan ser adaptadas a la vida personal y a las obligaciones familiares de los trabajadores, sin que implique la renuncia completa a ninguna de ellas. Y, en tercer lugar, se viene reclamando el principal papel de los poderes públicos que han de procurar unos servicios adecuados que atiendan el cuidado de las personas adultas dependientes y de las menores, en general $^{10}$.

En efecto, las licencias han tenido un protagonismo que, sin embargo, se ha revelado ineficiente, mientras que las jornadas flexibles de trabajo y, en general, los mecanismos que permiten la adaptación del tiempo de trabajo al tiempo "de no trabajo"11 se acomodan mucho más al objetivo de la verdadera conciliación. Y ello es así porque el estudio de estas figuras debe abordarse desde el prisma de la igualdad entre $\operatorname{sexos}^{12}$.

En el año 2016, la “Comisión Junker", incluyó entre su plan de trabajo la iniciativa "Un nuevo comienzo para hacer frente a los desafíos de la conciliación de la vida laboral y familiar", que pretendía incrementar la participación de las mujeres en el mercado de trabajo13. Con anterioridad, en julio de 2015, ante la falta de avances en su tramitación, se había anunciado la retirada de la propuesta de modificación de la Directiva relativa al permiso de maternidad14, de manera que esa nueva propuesta se presenta con un cariz

\footnotetext{
${ }^{10}$ Estudio de derecho comparado, RODRÍGUEZ RODRÍGUEZ, Emma, Instituciones de conciliación de trabajo con el cuidado de familiares, Bomarzo, 2010.

${ }^{11}$ Expresión muy reveladora de CASAS BAAMONDE, Ma . Emilia, "La organización del tiempo de trabajo con perspectiva de género: conciliación de la vida privada y la vida laboral”, op. cit., p. 19.

${ }^{12} \mathrm{El}$ 89\% de los cuidadores en España son mujeres, la mayoría cónyuges e hijas, con edades comprendidas entre los 45 y los 65 años, según cifras del Consejo Superior de Investigaciones Científicas (CSIC). En España el $85 \%$ de las mujeres siguen encargándose del trabajo doméstico y el $95 \%$ se ocupa del cuidado de los hijos (Eurostat).

13Comunicación de la Comisión al Parlamento Europeo, al Consejo y al Comité Económico y Social Europeo y al Comité de las Regiones, Programa de trabajo 2016: "No es el momento de dejar las cosas como están", Estrasburgo, 27 de octubre de 2015. COM (2015) 610 final.

14Propuesta de Directiva del Parlamento Europeo y del Consejo por la que se modifica la Directiva 92/85/CEE del Consejo, relativa a la aplicación de medidas para promover la mejora de la seguridad y salud en el trabajo de la trabajadora embarazada, que haya dado a luz o en periodo de lactancia. Bruselas, 3 de octubre de 2008, COM (2008) 637 final.
} 
amplio que pretende abrir "la vía a un nuevo enfoque para cumplir los objetivos estratégicos de mejorar la protección de las madres, lograr una mejor conciliación de la vida profesional y la vida familiar y facilitar la participación de las mujeres en el mercado de trabajo"15.

El 26 de abril de 2017, el Parlamento y el Consejo presentaron la propuesta de Directiva relativa a la conciliación de la vida familiar y la vida profesional de los progenitores y de los cuidadores, por la que se deroga la Directiva 2010/18/UE del Consejo16. Entre las razones y objetivos que la justifican, el propio texto de la propuesta enumera profusamente resultados sobre el fracaso de las medidas adoptadas hasta ahora, lo que ha abocado a las mujeres a una situación de infrarrepresentación en el empleo -trabajos a tiempo parcial, temporales o informales-. Las consecuencias inmediatas se trasladan a la brecha salarial de género, llegando a alcanzar el 28\% en algunos Estados miembros y el $40 \%$ de media en el UE, en el ámbito de las pensiones ${ }^{17}$. A la vez, critica abiertamente la carencia disposiciones que permitan que los hombres asuman las mismas responsabilidades familiares que las mujeres al no establecer permisos de cuidado equitativos y sin vinculación al género.

La nueva de Directiva (UE) 2019/1158, de 20 de junio $^{18}$, incluye una nueva clasificación de los permisos, diferenciando entre el de paternidad y el parental, a la vez que también mantiene el permiso por fuerza mayor, pero crea otro distinto que denomina "permiso para cuidadores". La duración será independiente entre cada permiso y se convierten en intransferibles. Así, se extenderán por diez días, el de paternidad; cuatro meses, el parental, y para cuidadores, un período mínimo de cinco días anualmente. Además, se eleva a 12 años la edad mínima del menor hasta la que se permite disfrutar de estos permisos, así como solicitar formas de trabajo flexibles con una duración de esas fórmulas que pueden someterse a límites razonables. Al mismo tiempo se refuerzan las garantías de disfrute de estos permisos a través de la consolidación de los derechos adquiridos o en curso de adquisición que se generen durante su disfrute, la protección económica, el desplazamiento de la carga de la prueba y se abre la puerta para que los Estados interpongan sanciones por incumplimiento, lo que supone un refuerzo a la protección frente a la desigualdad de trato o consecuencias desfavorables de quién se acoja a estos permisos.

Resulta fundamental, en cualquier caso, completar estos permisos específicos de alejamiento del puesto de trabajo, con las posibilidades de adaptación flexible al empleo, una vez que ha finalizado aquél o, incluso, durante su disfrute, en la medida que eso pueda facilitar la reincorporación del trabajador. Este es el punto clave y que marcará la

15Comunicado de prensa de la Comisión Europea, sobre el nuevo enfoque de la conciliación y la retirada de la propuesta de Directiva sobre la maternidad, Bruselas, 1 de julio de 2015.

16COM (2017) 253 final.

${ }^{17}$ En 2015, la tasa de empleo femenina (20-64 años) alcanzó el 64,3\%, frente al 75,9 \% en el caso de la masculina, "Closing the Gender Gap", OCDE (2013).

${ }^{18}$ Directiva (UE) 2019/1158, de 20 de junio, de Parlamento Europeo y del Consejo, relativa a la conciliación de la vida familiar y la vida profesional de los progenitores y los cuidadores, y por la que se deroga la Directiva 2010/18/UE del Consejo. 
diferencia respecto de la anterior regulación porque se refuerza el derecho a la reincorporación al trabajo tras el permiso parental.

La previsión de la anterior Directiva que animaba a los trabajadores y a los empresarios "a tomar disposiciones para definir medidas adecuadas para la reintegración" queda superada en la actual redacción del art. 9 de la nueva Directiva. Esta regulación responde a una previsión de carácter imperativo sobre la regulación del trabajo flexible que pretende incidir directamente en la corresponsabilidad, al fomentar el retorno al mundo laboral de la mujer, tradicional destinataria de los permisos parentales más extensos, con el consustancial riesgo de su desprofesionalización. En este nuevo reconocimiento se permite cierta limitación - como mínimo será hasta los 8 años- y requisitos -cierta antigüedad en el puesto-, pero se configura como un derecho subjetivo al que los Estados miembros deberán de dar cobijo en sus ordenamientos internos de manera que resulte efectivo, admitiendo que estas fórmulas de trabajo flexible puedan supeditarse a "límites razonables". En fin, como señala la Directiva se trata de que "las mujeres y los hombres deberán tener igual acceso a permisos especiales para cumplir con sus responsabilidades de cuidado y animárseles a utilizarlos de forma equilibrada".

En nuestro ordenamiento interno, el Real Decreto 6/2019, de medidas urgentes para la igualdad de mujeres y hombres ${ }^{19}$ ha introducido importantes modificaciones en materia laboral y de Seguridad Social recogiendo el espíritu de la norma europea sobre la individualización de los permisos de conciliación y en las fórmulas de trabajo flexible. Además de las adaptaciones terminológicas del propio texto legislativo para corregir un lenguaje desfasado y sexista ${ }^{20}$, debe mencionarse, si quiera resumidamente, que por fin se elimina la atribución preferente de derechos de conciliación de titularidad exclusiva o preferentemente femenina a favor de regulación de derechos de titularidad individual para cada progenitor, sin posibilidades de transferencia o con cuotas de reserva no intercambiables. Incluso puede afirmase que se va un paso más allá, al establecer acciones positivas para el ejercicio del trabajador masculino de los derechos de conciliación ${ }^{21}$.

Pero tal vez, en lo que se refiere al tiempo de trabajo y la conciliación, el avance más destacable -y deseado por la doctrina y los tribunales ${ }^{22}$ - se plasmó en la nueva redacción del derecho de adaptación de jornada del art. 34.8 ET. Su alcance objetivo hay que ponerlo en relación con el art. 37.4.5.6 ET, amparando ahora supuestos que no impliquen

\footnotetext{
${ }^{19}$ Real Decreto-ley 6/2019, de 1 de marzo, de medidas urgentes para garantía de la igualdad de trato y de oportunidades entre mujeres y hombres en el empleo y la ocupación. BOE de 7 de marzo de 2019.

${ }^{20}$ Sin ánimo de exhaustividad, destaca el cambio de "nacimiento" en lugar de "parto" o la sustitución de "la lactancia del menor" por "el cuidado del menor". Al respecto, NÚÑEZ-CORTÉS CONTRERAS, Pilar, "Avances en corresponsabilidad y flexibilidad en el cuidado del lactante y la adaptación de la jornada por motivos familiares”, Revista General de Derecho del Trabajo y de la Seguridad Social, nº. 55, 2020, p. 109.

${ }^{21}$ Al respecto, LOUSADA AROCHENA, Fernando y RON LATAS, Ricardo, "El permiso para el cuidado del lactante y la nueva prestación por su ejercicio corresponsable", Revista de Derecho Social y de Empresa, $\mathrm{n}^{\mathrm{o}} .12,2020$. https://www.dykinson.com/revistas/revista-derecho-social-y-empresa/

${ }^{22}$ SALA FRANCO, Tomás y BALLESTER PASTOR, $\mathrm{M}^{\mathrm{a}}$. Amparo, Reducción y Adaptación de la jornada por conciliación, Tirant lo Blanch, Valencia, 2009, p. 24 y ss.
} 
modificaciones de jornada necesariamente ${ }^{23}$. En realidad, según la literalidad del precepto, el nuevo régimen legal ampara el derecho de las personas trabajadoras "a solicitar" los cambios que considere oportunos en la duración y distribución de su jornada laboral para hacer efectivos sus derechos de conciliación de la vida familiar y laboral ${ }^{24}$. Esto ha llevado a buena parte de la doctrina a criticar la débil exigibilidad hacia quien se solicita $^{25}$, derivada de esta fórmula empleada por el legislador frente al reconocimiento indubitado de los derechos recogidos en el art. 37 ET. Justo este es el argumento empleado por alguna sentencia reciente que, con una interpretación restrictiva del derecho y desconectándolo de su componente de derecho fundamental ${ }^{26}$, deniega ese derecho a la trabajadora por entender que el art. 34.8 ET tan sólo contempla la posibilidad de solicitarlo y, en su caso, abre un período de treinta días para negociarlo con la empresa, supeditado a que el solicitante acredite las obligaciones de cuidado, no bastando la circunstancia de tener un hijo menor, ni que se trate de una gran empresa ${ }^{27}$.

A pesar de estas quiebras en la norma, la nueva configuración del derecho de adaptación de jornada, conjuntamente con el refuerzo de sus garantías procesales -se vincula con el art. 139, 1, a) LRJS-, han supuesto evidentes mejoras. Sin embargo, se ha hecho patente otra flaqueza como es el escrutinio al que se somete a la vida personal de la persona trabajadora que se ve obligada a acudir ante los tribunales para reclamar su derecho ${ }^{28}$. Una alternativa a este "escaparate" en el que se coloca la persona solicitante sería establecer parámetros objetivos determinados por el propio legislador -la negociación colectiva también podría jugar un papel destacado, aunque se plantean complicaciones si afecta a derechos de terceros- ante la existencia de más de un titular con obligaciones de

${ }^{23}$ LÓPEZ BALAGUER, Mercedes, "El derecho de adaptación de jornada y de modificación de la prestación", en AA. VV., Los derechos de conciliación en la empresa. Actualizado al RDLey 6/2019, de 1 de marzo, de medidas urgentes para garantía de la igualdad de trato y de oportunidades entre mujeres y hombres en el empleo y la ocupación, Tirant lo Blanch, Valencia, 2019, pp. 98-100. Al respecto también, STS 24 de julio de 2017, Rec. 245/2016, conversión a jornada continua amparada en el art. 34.8 ET.

${ }^{24}$ Se elimina el término "personal", en la misma línea que la propia Directiva (UE) 2019/1158, de 20 de junio, de Parlamento Europeo y del Consejo, relativa a la conciliación de la vida familiar y la vida profesional de los progenitores y los cuidadores, y por la que se deroga la Directiva 2010/18/UE del Consejo. Además, su escasa virtualidad en nuestro país, hace que no resulte especialmente relevante su supresión, al respecto, RODRÍGUEZ PASTOR, Gillermo, "Tiempo de trabajo tras la reforma operada por la LOI", en AA.VV., Los aspectos laborales de la Ley de Igualdad, Tirant lo Blanch, 2007, p. 80.

${ }^{25}$ Crítica con la legislación que considera "un tanto precipitada", BALLESTER PASTOR, Ma . Amparo, "De los permisos parentales a la conciliación: Expectativas creadas por la Directiva 2019/1158 y su transposición al ordenamiento español", Revista de Derecho a las Relaciones Laborales, $\mathrm{n}^{\circ} .11$, diciembre 2019, p. 1132.

${ }^{26}$ Por todas, sobre adaptación de jornada en un supuesto similar, STC 3/2007, de 15 de enero.

${ }^{27}$ STJ Galicia, de 5 de octubre de 2020. Rec. 2173/2020. Se trata de una trabajadora de Zara que pide una adaptación de jornada para tener libres los jueves por la tarde y los sábados por la mañana, aludiendo a que tiene un hijo de seis años; en su contra también está el hecho de que su marido y otro socio trabajen como autónomos en una empresa que regenta una oficina de Mafre, con independencia del horario de atención al público de éste, lo que se pone en valor por el fallo es que se pueda "autorganizar" con el socio. Aunque, a favor de este fallo hay que decir que resulta muy interesante el detenido análisis que realiza de la regulación en lid.

${ }^{28}$ Como ejemplos recientes, STJ/1 Cáceres de 15 de julio de 2019 (núm. 158/2019), en el que no se concede porque el cónyuge no trabaja los fines de semana; STJ 3/Gijón, de 29 de agosto de 2019 (rec.380/2109), recuerda la obligación del padre de cuidar al hijo y dado que no se aprecia restricción al respecto, le deniega su derecho a la trabajadora. análisis en el Blog. Prof. BELTRÁN HEREDIA, Ignasi, https://ignasibeltran.com/tiempo-de-trabajo-y-descanso/\#solicitudadaptaci\%C3\%B3n. 
cuidado sobre un mismo sujeto, de modo similar que hace el art. 48, i) del EBEP, con un marco temporal diferente en función de la persona que origina el derecho ${ }^{29}$. Sobre este aspecto se profundizará al referirse a las medidas de conciliación vinculadas al COVID19.

Aun así, dado el giro interpretativo realizado por el Tribunal Supremo ${ }^{30}$, este derecho a la solicitud de la adaptación de la jornada resulta más efectivo con la nueva regulación, tal y como demuestran los incipientes pronunciamientos judiciales al respecto ${ }^{31}$. Cierto es que ya desde la aparición del derecho del art. 34.8 ET la doctrina lo interpretó como "una especie de flexibilidad inversa" porque los poderes que aumentan no son los del empresario, sino los del trabajador. Y así se viene concibiendo en su versión actualizada como "un exponente de una mayor flexibilidad en favor de las personas trabajadoras" 32 . De este modo, el único condicionante en el que puede entrar la empresa es que las adaptaciones deberán de ser razonables y proporcionadas, tanto con las necesidades de las personas trabajadoras, como con las de la organización empresarial. Es decir, se trata de que, según las circunstancias de cada caso atendiendo a criterios de proporcionalidad, se garanticen ambos derechos de la mejor manera posible para ambas partes ${ }^{33}$.

A continuación, se analiza esta legislación junto con la normativa de urgencia adoptada para hacer frente a la situación de crisis provocada por la pandemia, con el objetivo de valorar el verdadero alcance de estas medidas en su cometido último de mantenimiento del empleo de todas las personas trabajadoras.

\section{Las medidas para favorecer la conciliación laboral frente al impacto social y económico del COVID-19}

En este contexto normativo, a penas transcurrido un mes de la Comunicación hecha pública el 26 de febrero sobre el Semestre Europeo $2020^{34}$, en el que se abrió el camino

\footnotetext{
29 "Si hubiera más de un titular de este derecho por el mismo hecho causante, el tiempo de disfrute de esta reducción se podrá prorratear entre los mismos, respetando en todo caso, el plazo máximo de un mes". Art. 48, i) Real Decreto Legislativo 5/2015, de 30 de octubre), Texto refundido de la Ley del Estatuto Básico del Empleado Público. BOE 31.10.2015.

${ }^{30}$ A favor de esta adaptación del tiempo de trabajo sin tener que acudir a la reducción de jornada, por todos, STS 24 de julio de 2017. Rec. 245/2016; sobre la interpretación de los tribunales y "el mediocre papel d la negociación colectiva en la articulación de los derechos de conciliación", MARTÍNEZ MORENO, Carolina, "La nueva regulación de la adaptación de la jornada con fines de conciliación. ¿Hasta dónde llega el avance?", Revista Derecho Social y de Empresa, n. 12, 2020, pp. 71-79.

${ }^{31}$ Alguna que se ha adelantado a la modificación legal, como la STJ Andalucía/Sevilla de 16 de mayo de 2019 (rec. 933/2019); otras: SJS Valencia 11 de febrero de 2020 (núm.396/2019), STS/6 Barcelona de 28 de noviembre 2019 (núm. 396/2019) o STS/1 Mataró, de 12 de septiembre de 2019 (núm. 642/2019); sobre estas resoluciones de primera instancia, análisis en el Blog. Prof. BELTRÁN HEREDIA, Ignasi, https://ignasibeltran.com/tiempo-de-trabajo-y-descanso/\#solicitudadaptaci\%C3\%B3n.

${ }^{32}$ LOUSADA AROCHENA, Fernando y RON LATAS, Ricardo, "El permiso para el cuidado del lactante y la nueva prestación por su ejercicio corresponsable", op. cit.

${ }^{33}$ NÚÑEZ-CORTÉS CONTRERAS, Pilar, “Avances en corresponsabilidad y flexibilidad en el cuidado del lactante y la adaptación de la jornada por motivos familiares”, op. cit., pp. 115-116.

34 "Semestre Europeo 2020: evaluación de los avances en las reformas estructurales y la prevención y corrección de desequilibrios macroeconómicos, resultados de los exámenes exhaustivos al Reglamento (UE) $n^{\circ}$. 1176/2011". https://op.europa.eu/es/publication-detail/-/publication/f03e0027-5942-11ea-8b81-
} 
a la implantación de un salario mínimo y una prestación por desempleo a escala europea, y pocos días después de que la Presidenta Van der Layen hubiese anunciado la nueva "estrategia para la igualdad de género 2020-2025"35, la crisis sanitaria pareja al COVID19 irrumpe en el territorio de la Unión, obligando a Italia, primero, y seguidamente a Portugal y a España a adoptar medidas de urgencia que permitan detener los contagios entre sus ciudadanos, a la vez que han de proteger el abastecimiento de los servicios esenciales.

En nuestro país, el mismo día de su publicación en el BOE, el 14 de marzo de 2020, entró en vigor el Real Decreto 463/2020, por el que se declara el estado de alarma para la gestión de la situación de crisis sanitaria ocasionada por el COVID-19. Se trata de una norma de enorme calado y transcendencia jurídica que ha abierto la espita legislativa a la que han ido adaptándose todos los estamentos del Estado ${ }^{36}$.

Como es sabido, entre sus medidas principales, la declaración del estado de alarma incluyó la suspensión de la actividad educativa presencial en todos los centros y niveles de enseñanza, pública y privada (art. 9) y, simultáneamente, todas las Comunidades Autónomas decretaron la suspensión de la actividad de los centros de atención diurna de servicios sociales. En efecto, los cierres de los centros educativos y de cuidado de mayores y dependientes suponen una de las cuestiones primordiales para frenar el contacto social, si bien, no todas las empresas van $\operatorname{cerrar}^{37}$ y muchas actividades pasaron a realizarse de manera on line. Por lo tanto, se plantea otro gran reto para el legislador de urgencia: gestionar el cuidado de esas personas más vulnerables -en las que se incluyen los no dependientes que puedan contagiarse, pero han de pasar el debido confinamiento en sus hogares- con las obligaciones laborales.

De manera muy especial, el Ministerio de Trabajo y Economía Social ha articulado un sistema de protección para trabajadores por cuenta ajena y para autónomos, en base a la regulación de los ERTE como medida principal de contención de la destrucción de empleo $^{38}$ y la minoración o eliminación de cuotas y la previsión de una prestación específica por cese de actividad, vinculados a los autónomos ${ }^{39}$. Pero, de manera sobresaliente, destaca la preocupación y la continuidad en la protección de los

\footnotetext{
01aa75ed71a1; al respecto, un análisis pormenorizado, el prestigioso Blog. Prof. ROJO TORRECILLA, E., http://www.eduardorojotorrecilla.es/2020/03/semestre-europeo-prioridades economicas.html.

${ }^{35}$ file:///C:/Users/USER/Desktop/gender_equality_strategy_factsheet_es.pdf

${ }^{36} \mathrm{Al}$ respecto, CASAS BAAMONDE, $\mathrm{M}^{\mathrm{a}}$. Emilia y RODRÍGUEZ-PIÑERO Y BRAVO FERRER, Miguel, "Un nuevo Derecho del Trabajo en la emergencia. Las medidas laborales y de seguridad social excepcionales en el estado de alarma declarado por la crisis sanitaria de Covid-19", Derecho de las relaciones laborales, $\mathrm{n}^{\circ}$. 4, 2020, pp. 317-348.

37 Como recuerda, LÓPEZ BALAGUER, Mercedes, "Los derechos de conciliación en la crisis del Covid19", El Derecho, n'. 2, junio, 2020, precisamente una de las excepciones a la prohibición de movilidad es el desplazamiento al lugar de trabajo para efectuar su prestación laboral, profesional o empresarial, según el art. 7, c) del RD 463/2020.

$38 \mathrm{Al}$ respecto, comentario técnico y preciso en el blog. Prof. BELTRÁN HEREDIA, Ignasi, https://ignasibeltran.com/2020/03/27/covid-19-y-erte-por-fuerza-mayor-situaciones-que-lo-justifican-yacreditacion/.

${ }^{39}$ Sobre esta cuestión, riguroso comentario del Prof. TALENS VISCONTI, Eduardo en el blog. "Foro Labos" https://forodelabos.blogspot.com/2020/04/el-decalogo-de-novedades-introducidas.html.
} 
trabajadores más vulnerables ${ }^{40}$, con referencias concretas a las consecuencias sobre el género. Resulta importante destacar ese leitmotiv en la abundantísima regulación de urgencia que ha obligado a desarrollar la situación de crisis sanitaria porque serán estas medidas de fuerte calado social, las que ofrezcan una sólida resistencia a los devastadores efectos sobre el empleo ${ }^{41}$.

El punto de partida en esta normativa lo constituyó el Real Decreto-Ley 8/2020, de 17 de marzo, de medidas urgentes extraordinarias para hacer frente al impacto económico y social del COVID-1942. Se trata de una norma extensa y bien fundamentada. De hecho, su Exposición de Motivos resulta muy clara, hasta didáctica. Así, identifica su triple objetivo en torno a "la protección de los trabajadores, las familias y los colectivos más vulnerables", "la continuidad de la actividad productiva y el mantenimiento del empleo", y a "reforzar la lucha contra la enfermedad".

\section{El carácter preferente del trabajo a distancia}

En base a estas premisas, en el Capítulo I se encuentran las "medidas para favorecer la conciliación laboral", que se articulan como un complemento y, en su caso subsidiarias, a la primera opción del legislador español que es "el trabajo a distancia", como mecanismo fundamental para mantener la actividad laboral en esta situación de restricción de la movilidad ciudadana. Hay que resaltar que nuestro país fue pionero en esta regulación que coinciden, en esencia, con las publicadas por la OIT en esas mismas fechas $^{43}$.

El "teletrabajo" se convierte en la principal herramienta en la que sustentar el trabajo por cuenta ajena, pero la norma también se refiere al "esfuerzo decidido por la preparación y dotación de las pymes al desarrollo digital", en concreto cita planes y programas estatales que ya estaban en marcha y que se agilizarán, para favorecer o consolidar la transformación digital ${ }^{44}$.

El carácter preferente del "trabajo a distancia" -expresión omnicomprensiva que se consolida en esta normativa de urgencia, en el mismo art. 5- como la apuesta más decidida del legislador para "garantizar que la actividad empresarial y las relaciones de trabajo se reanuden con normalidad tras la situación de excepcionalidad sanitaria", se concreta en varias obligaciones respecto de los sistemas de organización productivos. En particular, el empresario "ha de mantener la actividad por mecanismos alternativos", siendo para ello el principal ese tipo de trabajo en el domicilio, lo que implica, a su vez, que está

\footnotetext{
${ }^{40}$ Una excelente reflexión del Prof. TRILLO PÁRRAGA, Francisco en el blog. del Prof. BAYLOS GRAU, A., https://baylos.blogspot.com/2020/04/que-esta-cambiando-en-el-derecho-del.html.

${ }^{41}$ Además del análisis que se realizará a continuación de las normas más destacadas y específicas, los arts. 31 y 32 del Real Decreto-ley 11/2020, de 31 de marzo, regula el subsidio extraordinario por falta de actividad para las personas integradas en el Sistema Especial de Empleados de Hogar.

${ }^{42}$ BOE de 18 de marzo de 2020.

43 OIT, COVID-19 and world of work: Impacts and responses, Ginebra, 18 de marzo de 2020. https://www.ilo.org/global/topics/coronavirus

${ }^{44}$ Exposición de Motivos, p. 25856, BOE. Al respecto, FERNÁNDEZ NIETO, Livina A., "El teletrabajo: de actor secundario a protagonista en el escenario del COVID-19”, Diario La Ley, n. 9703, 24 de septiembre de 2020 .
} 
obligada, por un lado, a adoptar los mecanismos que lo hagan posible, con dos salvedades, una, "si ello es técnica y razonablemente posible", y otra, "si el esfuerzo de adaptación necesario resulta proporcionado". El mismo párrafo segundo del art. 5, termina su redacción insistiendo en que "estas medidas alternativas, particularmente el trabajo a distancia, deberán ser prioritarias frente a la cesación temporal o reducción de la actividad”. Queda muy claro el mandato del legislador respecto de otras alternativas de flexibilidad productiva clásicas en la gestión empresarial de las crisis anteriores a esta alarma sanitaria.

Es decir, el legislador impone que la actividad empresarial debe continuar, como primera premisa. Para ello, el trabajo que realizan sus empleados también debe proseguir preferentemente en la modalidad de "a distancia", con las adaptaciones técnicas que la actividad -y la empresa- puedan asumir por razones de oportunidad y de proporcionalidad. Estas dos obligaciones empresariales se subrayan como primordiales ante cualquier otra medida que conlleve la paralización de la actividad, total o parcialmente, así como la consiguiente destrucción de empleo, plena o reducida, que implicarían tales decisiones empresariales. Insiste el legislador sobre esta idea en el Real Decreto-Ley 10/2020, al señalar que quedan excluidas de las previsiones sobre el permiso retribuido recuperable las personas trabajadoras que puedan seguir desempeñando su actividad con normalidad mediante cualquier modalidad no presencial de prestación de servicios $^{45}$.

En aras de mantener esa actividad empresarial, el legislador aboga por una flexibilización de la, hasta ahora, exigente materia de seguridad y salud en el trabajo. En concreto, se dará por satisfecha la evaluación de riesgos inicial prevista en el art. 16 de la LPRL, en aquellos puestos y actividades que no hayan dispuesto de una anterior sobre el trabajo a distancia y se considera realizada a través de "una autoevaluación realizada voluntariamente por la propia persona trabajadora" 46 . Ahora bien, es importante destacar el reforzado "carácter excepcional" de la medida, como recuerda y subraya la propia previsión legal. Esa excepcionalidad debe alejar el riesgo de hacer "de la necesidad, virtud", que en este caso sería, al contrario, convertir la urgencia en la regla y que se eliminase la obligación empresarial de velar por la seguridad y salud en el trabajo, precisamente en este contexto en el que esa protección es el fin último de todas las decisiones gubernativas adoptadas.

En definitiva, la norma lleva a sus últimas consecuencias las previsiones del Convenio $\mathrm{n}^{\mathbf{o}}$. 155 OIT, sobre la seguridad y salud de los trabajadores, que hace responsable de tal derecho a las autoridades nacionales, al empresario y, en último término, protege al trabajador que unilateralmente "juzgue necesario interrumpir una situación de trabajo por

\footnotetext{
45 Así lo destaca LÓPEZ BALAGUER, Mercedes, "Los derechos de conciliación en la crisis del Covid19", op.cit.

46 al respecto, destaca el Prof. ROJO TORRECILLA, Eduardo, en la propuesta ante el consejo de ministros se había planteado, junto con la norma, un útil "cuestionario para el desarrollo del teletrabajo en el domicilio en situaciones temporales y extraordinarias"; se puede consultar en: https://media.timtul.com/media/adime/anexo\%20i\%20-\%20rd\%20covid19\%20en\%20el\%20ambito\%20laboral\%20-\%2017.03.2020_20200317172115.pdf
} 
creer, con motivos razonables, que ésta entraña un peligro inminente y grave para su vida o su salud".

Lo cierto es que los problemas y las dificultades del este tipo de trabajo se han hecho visibles más pronto que tarde. Así, Unicef, ONU Mujeres y la OIT advierten de que las familias trabajadoras necesitan más apoyo y piden un aumento de las medidas de protección social, especialmente para los más vulnerables ${ }^{47}$. En esta línea, hay quien ya ha llamado la atención sobre la necesidad de que se tenga en cuenta un concepto amplio de "trabajador", como sujeto protegido, intentando disipar las dudas que aun pudiesen albergar respecto de determinados colectivos especialmente desprotegidos -falsos autónomos- ${ }^{48}$.

Además, el sesgo de género también se hace evidente en esta crisis sanitaria, al repercutir en empleos feminizados, en gran medida. La OIT así lo ha constatado en relación con las trabajadoras sanitarias -enfermeras, limpiadoras, cuidadoras, en general, de centros de día, etc.- cuyo estrés laboral se encuentra doblemente aumentado ${ }^{49}$. Por eso, la flexibilidad en los horarios y en las franjas de disponibilidad laboral son unas de las medidas que se consideran primordiales para conjugar la actividad laboral con las responsabilidades familiares, mientras dure la crisis sanitaria con el consiguiente aislamiento social que impide la "externalización" de las laborales de cuidado de menores y dependientes.

En cualquier caso, la modalidad del trabajo a distancia, en tanto que se apoya fundamentalmente en los medios digitales de la organización empresarial debe acompañarse de una regulación concreta que delimite los tiempos de trabajo y descanso. En esta línea, la recién aprobada normativa "ordinaria" sobre el trabajo a distancia, constituirá sin duda un punto de inflexión ${ }^{50}$. Es importante tener en cuenta que la concreción de esta forma de trabajo va a alcanzarse por común acuerdo entre empresario y trabajador, bajo criterios de voluntariedad y de ser reversible, en todo momento. Habrá que ver su recorrido hacia la verdadera corresponsabilidad, pues no supone un avance en la regulación del art. 34.8 ET, que continúa observando la conciliación sin una auténtica perspectiva de género. Sobre esto se volverá al tratar el teletrabajo y su repercusión sobre el género.

Y será así porque el reciente Real Decreto 28/2020, en su DT $3^{\text {a }}$ excluye de su ámbito de aplicación "al trabajo a distancia implantado excepcionalmente en aplicación del art. 5 Real Decreto-ley 8/2020, o como consecuencias de las medidas de contención sanitaria

\footnotetext{
${ }^{47}$ Recomendaciones de UNICEF EAPRO, UNICEF ESARO y de la OIT, Family-friendly policies and other good workplace practices in the context of covid-19: key steps employers can take, de 27 de marzo de 2020.

${ }^{48}$ COUNTOURIS, Nicola, DE STEFANO, Valerio, EWING, Keith, y FREEDLAND, Mark, "Covid-19 crisis makes clear a new concept of 'worker' is overdue", Social Europe, vol. 2, 2020 https://www.socialeurope.eu/covid-19-crisis-makes-clear-a-new-concept-of-worker-is-overdue

${ }^{49}$ POZZAN, Emmanuela y CATTANEO, Umberto "Trabajadoras sanitarias: Trabajo sin descanso en hospitales y en el hogar", https://www.ilo.org/global/about-the-ilo/newsroom/news/WCMS_741192/lang-es/index.htm

${ }^{50}$ Real Decreto-ley 28/2020, de 22 de septiembre de trabajo a distancia. BOE de 23 de septiembre de 2020.
} 
derivadas de la COVID19" y, especifica que "mientras se mantengan, le seguirá resultando de aplicación la normativa laboral ordinaria". A parte de las dudas sobre la extensión de la vigencia del art. 5 RD-ley 8/2020 más allá de la declaración que puso fin al estado de alarma ${ }^{51}$, la norma transitoria presenta dificultades interpretativas, propias de la excepcionalidad en la que surge y en la que quiere mantenerla la nueva regulación que a sensu contrario, pretende ser estable y completa.

Atendiendo a la literalidad del precepto, debe entenderse que continuará rigiéndose por el art. 13 ET, desaparecido con el RD-ley 28/2020. Es decir, el art. 13 ET adquiriría de este modo una especie de "vigencia especial" extraordinaria constituyendo el marco de referencia normativo para ese tipo de "teletrabajo de la emergencia". De hecho, el legislador, consciente de las limitaciones de esa regulación, recoge expresamente en la Disposición Transitoria $3^{\mathrm{a}}$ la obligación del empresario de dotar al trabajador de "medios, equipos, herramientas y consumibles", a la vez que se remite a la negociación colectiva para acordar la posible compensación de gastos en que haya podido incurrir la persona trabajadora, fruto de la propia precipitación en el cambio de la forma de trabajar a la que obligó la pandemia. Aunque se trate de una regla transitoria, relacionada con una norma de respuesta ante el Covid-19, es positivo que el legislador haya incorporado como garante de derechos laborales a la negoción colectiva. Tal vez, la extrema urgencia sanitaria en la que aparece el RD-Ley 8/2020 desaconsejaba demorar más la medida sometiéndola a un proceso de negociación previo y era más efectivo optar por la imposición directa del trabajo a distancia. De hecho, el RD-Ley 21/2020, al referirse a las normas de seguridad e higiene de la "desescalada" insiste en potenciar el teletrabajo cuando por la naturaleza de la actividad laboral sea posible [(art. 7. 1e)].

La doctrina, ya en aquel momento inicial de la pandemia ${ }^{52}$, manifestaba la necesidad de contar con un marco normativo estable y actualizado sobre esta modalidad de trabajar que, sin resultar nueva completamente, se ha generalizado con una rapidez inusitada en las relaciones laborales de todo el mundo y también de nuestro país ${ }^{53}$. De hecho, la necesidad de contar con un marco normativo adaptado a la digitalización empresarial ya era uno de los retos del legislador español con anterioridad al COVID-19. Por lo tanto, esta especie de "teletrabajo forzoso" impuesto por el gobierno como medida extrema para mantener el distanciamiento social se ha mostrado como un instrumento útil a tal fin $-\mathrm{y}$ seguramente pueda serlo en otras circunstancias catastróficas de grandes desastres naturales, por ejemplo- pero debe considerarse excepcional y con un período de vigencia

\footnotetext{
${ }^{51}$ Blog. Prof. BELTRÁN HEREDIA, Ignasi, quien recuerda que la vigencia de este precepto se amplió en dos meses por el RD-Ley 15/2020, estando prevista inicialmente a un mes posterior al fin del estado de alarma, lo que se produjo en virtud del RD 555/2020, de 21 de junio.

${ }^{52}$ CRUZ VILLALÓN, Jesús, "Del coranavirus al contagio del teletrabajo", en Nueva Tribuna, 21 de marzo 2020,https://www.nuevatribuna.es/articulo/actualidad/coronavirus-confinamiento-teletrabajo-covid19oms-salud/20200320232306172385.html y en el Blog del mismo Profesor.

http://jesuscruzvillalon.blogspot.com/2020/03/del-coronavirus-al-contagio-del.html

${ }^{53}$ Casi 4 de cada 10 trabajadores en Europa comenzaron a teletrabajar, según Eurofound (2020), Living, working and COVID-19: First findings - abril 2020, Dublín.

https://www.eurofound.europa.eu/es/publications/report/2020/living-working-and-covid-19-firstfindings-april-2020
} 
absolutamente determinado por esa causa de fuerza mayor. Cuestión distinta es la regulación prevista en el RD-Ley 8/2020, de 22 de septiembre, que nace con la vocación de cubrir el vacío normativo que existía en nuestro ordenamiento jurídico y que se analizará más adelante en este trabajo como medida de flexibilización del tiempo de trabajo que puede influir en los derechos de conciliación.

\section{El Plan MECUIDA: adaptación y reducción de jornada}

Como respuesta a la crisis del COVID-19, el RD-Ley 8/2020 específicamente contempla especialidades en materias de la flexibilidad del tiempo y el modo de trabajo como medidas de conciliación que se regulan en los art.34.8 y 37.6.7 ET, respectivamente.

El denominado "Plan MECUIDA"-nomenclatura otorgada a posteriori por el art. 15 del RD-Ley 15/2020, de 21 de abril- que se prevé a partir del art. 6 del RD-Ley 8/2020, con vigencia hasta el 31 de enero de 2021 -ampliado recientemente por la Disposición Adicional $3^{\text {a }}$ del RD-Ley 28/2020-, articula un primer apartado con disposiciones comunes, a continuación se detiene en aspectos concretos respecto de la flexibilidad horaria, considerándola un instrumento prioritario frete a la reducción de jornada, que regula como última alternativa.

Según el art. 6.1, el ejercicio de estas medidas de conciliación corresponderá a "las personas trabajadoras que acrediten deberes de cuidado" respecto de los sujetos causantes concretos: el cónyuge o pareja de hecho y los familiares "hasta segundo grado de consanguineidad". Por lo tanto, la titularidad se circunscribe a los trabajadores por cuenta ajena con obligaciones de cuidado a su cargo. No parece que se eche en falta alguna mención en relación con los autónomos o funcionarios, por contar con sendas normativas especiales y el diferente alcance de las notas de subordinación y dependencia que las caracterizan $^{54}$.

Más específicas son las previsiones sobre los sujetos causantes. La inclusión del cónyuge o pareja de hecho es más explícita que la del Estatuto, sin duda como una medida de refuerzo respecto de cualquier tipo de pareja de hecho, esté inscrita legalmente o no. Sobre los familiares, en cambio, la limitación a familiares de segundo grado de consanguineidad sí supone una novedad respecto del art. 37.6 ET, al descartar, de este modo, a los familiares afines ${ }^{55}$. A pesar de alguna opinión contraria ${ }^{56}$, la previsión ya se recoge en el $\mathrm{EBEP}^{57}$ y hace tiempo que la doctrina viene reclamando que se haga extensible al régimen laboral común justamente para influir en el reparto de los cuidados

\footnotetext{
${ }^{54}$ En el caso de los autónomos, el propio art. 49, j) EBEP prevé un permiso general por necesidades de conciliación. En el caso de autónomos, ni que decir tiene que el tiempo de trabajo entra dentro de sus capacidades de autorganización.

55 Al respecto, más detallado, BLASCO PELLICER, Ángel, LÓPEZ BALAGUER, Mercedes, ALEGRE NUENO, Manuel, RAMOS MORAGUES, Francisco, TALÉNS VISCONTI, Eduardo, Análisis normativo de las medidas laborales y de seguridad social frente a la crisis del COVID-19", Tirant lo Blanch, Valencia, 2020.

${ }^{56}$ BARRIOS BAUDOR, Gillermo L., “Adaptaciones y/o reducciones especiales de jornada con ocasión de la crisis sanitaria COVID-19: Plan MECUIDA”, Revista Aranzadi Doctrinal, nº 6, 2020 (BIB 2020\12109). ${ }^{57}$ Art. 48, i) EBEP.
} 
entre las personas que deban hacerse cargo de los mismos ${ }^{58}$. Hay que entender que la ausencia de más matices sobre la legislación ordinaria implica que los hijos e hijas puedan ser igualmente sujetos causantes ${ }^{59}$.

En cuanto a la acreditación de la necesidad de cuidado, nada señala en un principio sobre la fórmula específica, por lo que se entenderá que será válida cualquiera admitida en derecho. No obstante, en el párrafo siguiente se delimitan las circunstancias excepcionales relacionadas con el Covid-19 que la persona solicitante deberá de acreditar.

Comienza por referirse al cuidado "personal y directo" que como consecuencia del Covid19 necesite alguno de los sujetos causantes por razones de edad, enfermedad o discapacidad. Es decir, cuando las personas indicadas en el precepto anterior se encuentren enfermas de coronavirus o en situación de cuarentena. La referencia al cuidado "personal y directo" puede entenderse vinculada al presupuesto de corresponsabilidad al que a continuación se hará referencia.

A continuación, menciona como causa justificativa el cierre de los centros educativos o de cualquier otra naturaleza que dispensaran cuidado o atención a los sujetos causantes. En efecto, la obligación de prestar esas atenciones por los familiares que trabajan les obliga a solicitar cambios en sus horarios que se ajusten a esas atenciones que antes podían delegar en los centros especializados. De hecho, esta es la mayor problemática a la que se enfrentan las autoridades ante un segundo confinamiento domiciliario generalizado, razón por la que países como Alemania han dejado abiertas las escuelas ${ }^{60}$.

Por último, establece como causa justificativa la atención del sujeto causante que con anterioridad haya recaído en un tercero y por causas relacionadas con el Covid-19, sea imposible que continúe haciéndolo. Principalmente esta circunstancia afectará a las personas empleadas de hogar y, especialmente, a aquéllas especialistas en materias de cuidado. También puede darse el caso de que la persona cuidadora pertenezca a la unidad familiar, pero enferme o deba de guardar cuarentena por riesgo de haber contraído el virus. Es decir, que por una causa de fuerza mayor la persona cuidadora no pueda seguir dispensando esas atenciones. Téngase en cuenta que respecto de las empleadas de hogar se aprobó con posterioridad a ésta una regulación especial que contempla la posibilidad de suspender temporalmente el contrato según los artículos 30 y siguientes del RD-Ley $11 / 2020$, de 31 de marzo.

En fin, como se ha advertido acertadamente por la doctrina, se trata de supuestos independientes entre sí que, de darse conjuntamente, únicamente refuerzan la pretensión de la persona trabajadora, pero basta con que se produzca uno sólo de ellos ${ }^{61}$.

Para terminar con los presupuestos comunes, destaca que se configura como un derecho individual de conciliación de la persona que los solicita. Se trata de una fórmula ya

\footnotetext{
${ }^{58}$ Otra cosa son las obligaciones civiles de cuidado entre familiares que establece el Código Civil en los arts. 142 y siguientes, sobre las obligaciones de alimentos y los derechos de patria potestad.

${ }^{59}$ LÓPEZ BALAGUER, Mercedes, "Los derechos de conciliación en la crisis del Covid-19", op. cit.

${ }^{60}$ www.deutschland.de: https://www.deutschland.de/en/corona-virus-germany-overview

${ }^{61}$ BARRIOS BAUDOR, Gillermo L., "Adaptaciones y/o reducciones especiales de jornada con ocasión de la crisis sanitaria COVID-19: Plan MECUIDA", op. cit.
} 
incorporada en nuestro ordenamiento, sobre todo a partir del RD-Ley 6/2019, que va en la línea de la normativa y de la jurisprudencia europea sobre la titularidad de los derechos de conciliación, sin que quepan diferencias entre los titulares por el tipo de contrato o, incluso, porque uno de ellos no trabaje.

Más significativas son las exigencias sobre la justificación de las medidas sobre el reparto corresponsable de las obligaciones de cuidado y la evitación de la perpetuación de roles. En esta línea encaja perfectamente la propia exclusión prevista por el legislador sobre los familiares afines dentro de los sujetos causantes. Además, resulta coherente por el mandato de la nueva Directiva 1158/2019, pero también concuerda con el juicio "justificado, razonable y proporcionado" según las circunstancias concurrentes de cada caso - tanto la capacidad empresarial de adaptación, como el hecho de que lo soliciten varios trabajadores- que ya venía aplicando la jurisprudencia en nuestro país ${ }^{62}$. Sin duda la previsión legal resulta un avance hacia la deseada corresponsabilidad en las labores de cuidado y debe entenderse que el solicitante tiene que explicar cómo se repartirá para atender a esas tareas junto con el otro progenitor o cuidador que pudiese existir.

A mayor abundamiento, tanto la doctrina como la jurisprudencia vienen reforzando la idea del disfrute de las reducciones y adaptaciones de jornada desde el prisma de la proporcionalidad y el reparto en las obligaciones de cuidado, al configurarlo, en último término como una parte esencial del derecho a la igualdad y no discriminación previsto en nuestro texto constitucional. Esto hará que en caso de existir controversias en su disfrute o reconocimiento deba acudirse al procedimiento especial del art. 139 LJS, como la propia norma de urgencia señala al englobarlos dentro del "ejercicio de los derechos de conciliación a todos los efectos". Es una previsión adecuada y efectiva, siempre que no se trate de fases de confinamiento severo con la suspensión de la actividad administrativa y judicial, como ocurrió en una etapa.

Finalmente, el apartado cuatro del precepto recoge la posibilidad de que las personas trabajadoras que ya estuviesen disfrutando de medidas de conciliación de legalidad "ordinaria", puedan ahora solicitar su paralización y acogerse a estos nuevos instrumentos jurídicos que, a la sazón, se adaptarán mejor a la extraordinaria realidad derivada de la pandemia. En todo caso, tendrán que cursar la oportuna solicitud, limitada temporalmente al período de la crisis y justificada, al igual que el resto de solicitantes, con los requisitos debidamente acreditados que se exigen para el resto, si bien en este supuesto, por venirse disfrutando ya con anterioridad, se considerará que se trata de una medida razonable y proporcionada, salvo prueba en contrario ${ }^{63}$.

En cuanto a la adaptación del tiempo de trabajo, el art. 6.2 RD-Ley 8/2020, con base en la previsión del art. 34.8 ET, introduce matizaciones para dotarla de la máxima inmediatez en su aplicación práctica. Tal vez lo más destacado resulta la prerrogativa ex lege del criterio de la persona trabajadora en la concreción de la adaptación. Ciertamente el

${ }^{62}$ Así se ha visto ya en relación con numerosos pronunciamientos que entran a valorar cuestiones absolutamente personales bajo el paraguas de la esta evaluación proporcional; otras, por todas, STSJ de Galicia de 28 de mayo de 2019, rec. 1492/2019.

${ }^{63}$ LÓPEZ BALAGUER, Mercedes, "Los derechos de conciliación en la crisis del Covid-19", op. cit. 
carácter temporal y excepcional de estas previsiones justifican este imperativo legal, aunque también se reafirma claramente el intento de acuerdo previo como fórmula deseable. En este sentido, debe entenderse que el plazo de negociación individual del art. 34.8 ET no será aplicable porque el precepto perdería su finalidad principal, por lo que el período de negociación debe reducirse a lo mínimo imprescindible ${ }^{64}$-días y horas, a ser posible-, incluso con preferencia a la norma convencional que pudiese existir.

La medida de conciliación, en este caso, puede referirse tanto a la distribución de tiempo de trabajo, como a cualquier otro aspecto de las condiciones de trabajo - por si hay dudas, el precepto especifica la "alteración de horario, horario flexible (...) cambio de funciones, cambio de centro, cambio en la forma de prestación del trabajo (...)"- justificando su aplicación desde una perspectiva corresponsable y proporcionada a las necesidades de organización de la empresa. Así, podrá requerirse cierta concreción en la organización de esos tiempos conjuntamente con la otra persona responsable de prestar el cuidado al sujeto causante, lo que en casos de familiar monoparentales no debería ser necesario.

Los sujetos causantes serán los referidos en el art. 34.8 ET, es decir, los hijos e hijas menores de 12 años de edad y, a mayores, se extenderá a los familiares a los que se refiere el propio art. 6.1 RD-Ley 8/2020. Por lo tanto, los menores a cargo de la persona trabajadora, aun cuando sean mayores de 12 años, sí podrán justificar una medida de adaptación de la forma o el horario de trabajo de la persona trabajadora que deba cuidarlo si se encuentra en uno de los tres supuestos derivados directamente del Covid-19, como señala la norma de urgencia.

Por lo que se refiere al recurso a la reducción de jornada regulada en el art. 37.6 ET, el art. 6.3 RD-Ley 8/2020 también ha establecido especialidades para dar respuesta a la situación de pandemia. Lo más innovador es la previsión que posibilita la reducción de la jornada al cien por cien, si fuese necesario. Dada la reducción proporcional del salario, el recurso a esta medida podría parecer vacía de contenido. Sin embargo, quien reduzca su jornada por necesidades de cuidado derivadas del Covid-19 podrá mantener su puesto de trabajo, sin necesidad de acudir a los procedimientos de legales ordinarios o a los que pueda prever el convenio colectivo de aplicación que serán menos ágiles. Tanto es así, que el preaviso de la reducción de jornada especial deberá ser comunicada a la empresa con sólo 24 horas de antelación, en lugar de los quince días que, en defecto de convenio, marca el ET.

Además, a esta reducción de jornada, deberán resultar aplicables todas las garantías del art. 37. 6 y 7 ET y demás normativa que atribuya una protección especial para la persona trabajadora que ejercita sus derechos de conciliación [protección frente al despido, arts. 53.4, b) y 55.5, b) ET, así como prestaciones familiares contributivas, art. 237.3 y 4 LGSS], dado que la protección de la norma de urgencia resulta un refuerzo sobre la legislación ordinaria, tal y como señala la propia exposición de motivos del RD-Ley 8/2020. En ningún caso, por tanto, cabría entender que estos derechos de conciliación gozan de una protección inferior respecto a los ordinarios, pues para ese viaje no nos

\footnotetext{
${ }^{64}$ Ibidem.
} 
harían falta estas alforjas, si se me permite la expresión. En definitiva, se trata de que las solicitudes de reducción de jornada en pro de la conciliación se favorezcan por la empresa en todo lo posible, dada la situación de excepcionalidad provocada por la crisis sanitaria.

Como ya se ha advertido, el RD-Ley 28/2020 ha prorrogado la vigencia de estas medidas del Plan MECUIDA hasta el 31 de enero de 2021. El motivo resulta obvio, continúan existiendo situaciones vinculadas a la pandemia en la que se hacen necesarios estos derechos de conciliación "específicos" para el Covid-1965. La apertura de las aulas ha implicado problemáticas originadas por confinamientos de menores que encuentran respuesta legal para afrontarlos en estas previsiones. La doctrina ha considerado positivo este alargamiento de plazos, a pesar de que echa en falta una apuesta más decidida por las medidas de adaptación frente a los de ausencia de la persona trabajadora ${ }^{66}$ para evitar la desprofesionalización de quien se aparte del mercado laboral, al menos en parte, y que las estadísticas nos indican que son fundamentalmente mujeres.

Esta crítica se comparte parcialmente, pues el legislador de urgencia ha incluido entre los requisitos generales que ha de acreditar el solicitante de la reducción, la corresponsabilidad en los cuidados, cuestión ausente completamente en la norma legal ordinaria y que impide contemplar ese reparto equitativo de las labores de cuidados entre todos los que tengan derecho a ejercitarlo. No obstante, se comparte plenamente la propuesta de favorecer de manera decida a las adaptaciones de jornada frente al alejamiento del trabajo que provoca perversos desajustes sobre los derechos laborales y de Seguridad Social de las personas que se acogen a ellos ${ }^{67}$. Por ejemplo, podría apostarse por prever algún tipo de bonificación en las cotizaciones de Seguridad Social, tanto para empresas como para trabajadores, de forma que les saliese "más a cuenta" la adaptación que la reducción.

En fin, el Covid-19, sin duda, ha obligado a que la conciliación se observe con mayor interés por los legisladores y las empresas, conscientes de la necesidad de gestionar los tiempos de trabajo y de no trabajo de las personas trabajadoras con una perspectiva de género. Al respecto, el "teletrabajo" parece ser una especie de panacea. A continuación, se analizará esta nueva -o más generalizada desde la pandemia- forma de trabajo caracterizada por su flexibilidad en los intervalos temporales del trabajo y de la vida privada.

\footnotetext{
${ }^{65}$ Sobre la previsibilidad del alargamiento de la vigencia de estas medidas, hace meses, la doctrina ya lo adelantaba como una necesidad para dar cobertura legal a esas futuras situaciones. Al respeto, BARRIOS BAUDOR, Gillermo L., "Adaptaciones y/o reducciones especiales de jornada con ocasión de la crisis sanitaria COVID-19: Plan MECUIDA", op. cit. y LÓPEZ BALAGUER, Mercedes, "Los derechos de conciliación en la crisis del Covid-19", op. cit.

${ }^{66}$ GOERLICH PESET, José M" "Vuelta al 'cole' en el contexto de la Covid-19: problemas de conciliación de la vida laboral y familiar", Blog. Foro de Labos, https://forodelabos.blogspot.com/2020/09/vuelta-alcole-en-el-contexto-de-la.html

${ }^{67}$ BLASCO JOVER, Carmen, "Tres preguntas (con respuesta) sobre la excedencia por cuidado de hijos: cuando se requiere reformar la norma para ampliar su protección”, Revista de Derecho Social, nº. 86, 2019, pp. 79-95.
} 


\section{El teletrabajo y los derechos de conciliación de calidad}

Tradicionalmente la relación entre las nuevas tecnologías y las condiciones laborales se ha planteado desde una perspectiva positiva, en el sentido de que serían un medio para facilitar la conciliación de las obligaciones laborales y familiares. De hecho, el Parlamento Europeo, en marzo del año 2018, instó a los Estados miembro para que favorezcan las posibilidades de la flexibilidad en la organización laboral, (...) "de manera que se aproveche todo el potencial que ofrecen las nuevas tecnologías" $(\ldots)^{68}$.

En efecto, la Estrategia para la igualdad de Género 2020-2025, de la Comisión Europea, se ha referido a las fórmulas de trabajo flexible como la mejor alternativa para conseguir un verdadero avance en los derechos de conciliación de las personas trabajadoras. Eso sí, siempre que se vigile y promuevan bajo el prisma del reparto equitativo de las responsabilidades asistenciales entre ambos progenitores. Insiste en que "la Comisión velará por que los Estados miembros transpongan y apliquen correctamente esta Directiva -Directiva 2019/1158, relativa a la conciliación- de forma que los hombres y las mujeres puedan prosperar en igualdad tanto a nivel personal como profesional".

No obstante, desde los primeros intentos de la instrumentalización del teletrabajo en aras de la compatibilidad de la vida laboral y familiar, se ha observado que propicia todo lo contrario para la trabajadora -el sesgo de género es prácticamente uniforme- que opta por ella, al suponer una fuerte atadura al rol social de cuidadora e implicar importantes quiebras en la protección de la seguridad y salud ${ }^{69}$. De hecho, se critica la utilización fraudulenta que se hace del mismo por parte de un perfil determinado de "nuevos" trabajadores cualificados - en estos casos, hombres, fundamentalmente- que se han beneficiado de esas posibilidades de flexibilización para poder incrementar su autonomía en la prestación de sus servicios, sin que ello responda a sus necesidades reales de conciliación ${ }^{70}$.

Otro inconveniente es que parece que, con la automatización de los instrumentos de trabajo, la cotidianeidad en la utilización de los medios tecnológicos en las propias relaciones laborales hace que resulte cada vez más difícil delimitar la jornada de trabajo y separar nítidamente el tiempo de descanso del hecho de "estar conectado" al trabajo. Se trata de la llamada tendencia al "well-being", como el paso siguiente al "work-life balance" y el "work life management". De esta forma se diluyen las fronteras entre lo

\footnotetext{
${ }^{68}$ Parlamento Europeo, de 14 de marzo de 2018, sobre el Semestre Europeo para la coordinación de las políticas económicas, op. cit.

${ }^{69}$ Excelente y completo estudio sobre la repercusión de las TICs en el acceso al empleo de las mujeres y su repercusión sobre la seguridad y salud, MELLA MENDEZ, Lourdes, "Mujer trabajadora y empleo tecnológico: medidas de actuación urgente contra la brecha digital de género", Trabajo y Derecho, $\mathrm{n}^{\circ}$. 66, 2020. En la misma línea, PUEBLA DE LA PINILLA, Ana, "El trabajo de las mujeres en la era digital", Trabajo y Derecho, 2019, nº. 58.

${ }^{70}$ Sobre la ausencia de perspectiva de género en el teletrabajo y su repercusión en las condiciones de empleo de las trabajadoras, FERNÁNDEZ PROL, Francisca, "Relaciones de trabajo ante el proceso de digitalización de una economía: análisis desde una óptica de género", Revista de Derecho Social, nº 89, 2020, pp. 107-119.
} 
profesional y lo personal, tanto que se promueve que ahora se integran y se confunden para eliminar el conflicto entre ambos aspectos de la vida ${ }^{71}$.

Ahora bien, el pretendido equilibrio que defiende esa teoría se quiebra cuando el trabajador se va a considerar más productivo y, por lo tanto, más valioso en cuanto se muestre más "disponible" a las necesidades de la empresa en todo momento. Es decir, la "doble innovación tecnológica-organizativa" se sustenta, en gran medida, en que ahora el empresario goza de la posibilidad desmedida de la distribución irregular de la jornada, pero favoreciendo su incremento, en lugar de reducirlo ${ }^{72}$.

Así pues, son dos los desafíos principales las que plantea el teletrabajo y, en general, el trabajo a distancia, en el contexto de la digitalización empresarial. Por un lado, constituir un instrumento eficaz para ejercer los derechos de conciliación y, simultáneamente, garantizar un derecho al descanso de calidad.

Ya se ha anticipado que el RD-Ley $28 / 2020$ ha sido la norma que el legislador español acaba de aprobar para regular esta nueva forma de organización del trabajo, cuyo ámbito objetivo dejará fuera al denominado "teletrabajo ocasional" 73 , pues sólo se aplicará al trabajo a distancia realizado con cierta regularidad, en concreto, "un mínimo de un treinta por ciento de la jornada" en un período de tres meses. La norma delimita los conceptos de teletrabajo y otros aspectos definitorios. Además, establece las características básicas para su adopción, comenzando por la voluntariedad de ambas partes en el acuerdo individual por el que se acuerde y continuando por destacar que será reversible, también por ambas partes, en cualquier momento. Las garantías de estos trabajadores a los derechos colectivos e individuales se reconocen idénticos a los de trabajadores presenciales. La mayoría de las previsiones legislativas vienen a recoger las establecidas en el Acuerdo Marco Europeo sobre Teletrabajo ${ }^{74}$.

Bajo la perspectiva actual de emergencia sanitaria, parece muy adecuado acelerar y potenciar estas incipientes formas de prestación laboral en nuestro país y, en algún sector, muy generalizados por el contrario en el norte de Europa. Conviene, por tanto, acelerar estas políticas de flexibilidad de horarios y de presecialidad en el trabajo, como el mejor remedio para el mantenimiento del empleo, cuando sea posible su desarrollo on line.

\footnotetext{
71 USHAKOVA, Tatsiana, "De la conciliación a la desconexión tecnológica. Apuntes para el debate", Revista Española de Derecho del Trabajo, n. 192, 2016, parte Estudios (BIB 2016/85593).

72 MOLINA NAVARRETE, Cristóbal, "Jornada laboral y tecnologías de la infocomunicación: 'la desconexión digital', garantía del derecho al descanso", Temas Laborales, no. 138, 2017, p. 225. RODRÍGUEZ RODRÍGUEZ, Emma, "La transcendencia de la disponibilidad horaria del trabajador en el contexto de las plataformas digitales", Temas Laborales, n. 146, 2019, pp. 131-148.

${ }^{73}$ El Prof. Wilfredo Sanguineti lo pone de manifiesto y critica que esa falta de cobertura pueda dejar fuera de la protección a mucho del trabajo a distancia que se hace con fines de conciliar. https://wilfredosanguineti.wordpress.com/2020/10/03/la-ley-de-trabajo-a-distancia-o-las-dificultades-deconciliar-dos-necesidades-de-distinto-origen/

74 Confederación Europea de Sindicatos (CES), la Unión de Confederaciones de la Industria y de Empresarios de Europa (UNICE) / la Unión Europea del Artesanado y de la Pequeña y Mediana Empresa (UNICE/UEAPME) y el Centro Europeo de la Empresa Pública (CEEP) han firmado un acuerdo marco sobre el teletrabajo a fin de dar más seguridad a los teletrabajadores por cuenta ajena en la UE, en el año 2002 y fue revisado en 2009.
} 
Puede afirmarse que nos encontramos ante una nueva forma de trabajar que se caracteriza por su flexibilidad y mayor capacidad de adaptación a las circunstancias personales del trabajador. Ahora bien, como a continuación se explicará, en ningún caso se refiere a la conciliación como una finalidad de esa forma de trabajo. De hecho, tal vez, lo más complicado en la situación actual para los poderes públicos, es asegurar el reparto de esas tareas de cuidado, sin que las precarias condiciones laborales de partida vinculadas al rol de género - brecha salarial, la repercusión del techo de cristal respecto del puesto ocupado, ...- supongan una doble penalización para las mujeres trabajadoras.

La desvinculación jurídica del teletrabajo o trabajo a distancia respecto del ejercicio de los derechos de conciliación ha quedado patente con la actual regulación urgencia frente a la pandemia. Ya se ha comentado que el RD- Ley 8/2020 diferencia entre ambos de manera clara los preceptos 5 y 6 , respectivamente. Ello no obsta para a que sea posible solicitar una adaptación de jornada cuando se teletrabaja. Y esto es aplicable durante la pandemia, pero también fuera de la excepcionalidad de ese momento. El art. 34.8 ET, como se ha comentado, permite que cualquier trabajador -incluido el teletrabajadorsolicite la adaptación de la duración y distribución de la jornada ${ }^{75}$.

Precisamente, el RD-Ley 28/2020 en el art. 4.3 reconoce el derecho de los teletrabajadores a ser tomados en consideración para elaborar los planes de igualdad de las empresas, y en el 4.5 se reafirma la equiparación de derechos de conciliación y de corresponsabilidad con los trabajadores presenciales, incluyendo la adaptación a la jornada del art. $34.8 \mathrm{ET}^{76}$. Resulta positiva la llamada del art. 8.3, párrafo segundo, a la negociación colectiva o a otros acuerdos entre la empresa y los representantes de los trabajadores para evitar el peligro intrínseco a estas formas de trabajo de perpetuar los roles de género. Específicamente se advierte de este peligro y se impone el fomento de la corresponsabilidad como "objeto de diagnóstico y tratamiento por parte del plan de igualdad".

Por su parte, la modificación prevista en la Disposición Final $2^{\text {a }}$ del RD-Ley 28/2020 sobre la LJS extiende la aplicación del art. 139 al trabajador a distancia. Sobre esta cuestión la doctrina ${ }^{77}$ se ha cuestionado la verdadera voluntariedad del empresario cuando el trabajo a distancia se solicite en base al ejercicio de derechos de conciliación. Es verdad que resultará cuestionable esa característica pues ahora la solicitud del trabajo a distancia prevista en el art. 34.8 ET se ve reforzado por una regulación especial que configura su desarrollo. No obstante, esta normativa busca equilibrar y equiparar los derechos de los trabajadores a distancia con los presenciales, de modo que una vez que se trasforme su forma de prestar el trabajo, se le aplicarán las peculiaridades del trabajo a distancia por conciliación que podrán constar en el acuerdo al que hayan llegado las partes.

\footnotetext{
${ }^{75}$ MARTÍNEZ MORENO, Carolina, "La nueva regulación de la adaptación de la jornada con fines de conciliación. ¿Hasta dónde llega el avance?”, op. cit., pp. 71-73.

${ }^{76}$ Llama la atención sobre esta postura legislativa FERNÁNDEZ NIETO, Livina A., "El teletrabajo: de actor secundario a protagonista en el escenario del COVID-19", op. cit.

${ }^{77}$ LÓPEZ BALAGER, Mercedes, "La voluntariedad del trabajo a distancia en el RDL 28/2020: ¿es el derecho al trabajo a distancia por conciliación una excepción?, Blog. Foro de Labos, https://forodelabos.blogspot.com/2020/10/la-voluntariedad-del-trabajo-distancia.html
} 
En cuanto a las previsiones sobre el trabajo a distancia previsto dentro del Plan MECUIDA, la Disposición Transitoria $3^{\mathrm{a}}$ vincula esta medida a la situación de crisis sanitaria, vinculada con ella directamente, lo que supone una exclusión del ámbito de aplicación del RD-Ley 28/2020. Sobre el art. 5, ya se ha advertido que ha decaído su vigencia, salvo para situaciones adoptadas con anterioridad. Aun así, recoge obligatoriedad empresarial en la dotación de medios y herramientas y del mantenimiento de los equipos a la persona trabajadora a distancia, lo que cabe extenderse, por analogía, hacia aquellas que se acojan a medidas de conciliación prorrogadas del Plan MECUIDA, que continuarán reguladas por el régimen de emergencia ${ }^{78}$.

Más allá de la regulación de urgencia, cabría preguntarse qué capacidad para negarse tendrá el empresario sobre las peticiones de adaptación de jornada y, sobre todo, de nuevas formas de trabajo a distancia, en tanto que se realizan bajo el amparo del ejercicio de derechos de conciliación, cuya naturaleza como derechos fundamentales resulta indubitada. Es verdad que el art. 139 LJS establece una vía óptima, por su propia configuración, para resolver en un plazo adecuado la cuestión y siempre bajo el prisma de los derechos ejercidos corresponsablemente.

No obstante, podría caerse en una segregación por género de las personas trabajadoras que se acojan a estos derechos, perpetuando el rol de cuidadoras y revolviendo miedos superados del pasado, como la vuelta a la "doble jornada". El teletrabajo puede propiciar la conciliación, al permitir más flexibilidad en la adaptación del trabajo, pero no es en sí misma una medida conciliadora. Como señala la OIT en su Guía práctica sobre el teletrabajo, los empleadores deberían seguir promoviendo políticas y medidas favorables a la familia y, es más, "alentar a los hombres a compartir por igual las responsabilidades del cuidado no remunerado y de las tareas domésticas"79.

En fin, habrá que esperar para analizar con más calma la puesta en práctica de estas normativas conjuntamente, la del trabajo a distancia y las relacionadas con los derechos de conciliación y, no olvidar ese prisma de la corresponsabilidad que el legislador recuerda en todas las Exposiciones de Motivos de las últimas normas.

El otro gran estigma del teletrabajo es que se agravan los conflictos entre el trabajo y la vida privada, en especial la gestión de los límites entre el tiempo de trabajo y el personal para descansar y desconectar de las obligaciones laborales.

\footnotetext{
78 Al respecto, duda sobre esta afirmación, blog. Prof. BELTRÁN HEREDIA, Ignasi, https://ignasibeltran.com/2020/10/05/breves-notas-que-normas-deben-aplicarse-al-trabajo-a-distanciaadoptado-en-el-marco-del-covid19-tras-el-rdley-28-2020/

A favor de tal interpretación, LÓPEZ BALAGER, Mercedes, "La voluntariedad del trabajo a distancia en el RDL 28/2020: ¿es el derecho al trabajo a distancia por conciliación una excepción?, Blog. Foro de Labos, https://forodelabos.blogspot.com/2020/10/la-voluntariedad-del-trabajo-distancia.html

79 OIT, El teletrabajo durante la pandemia de COVID-19 y después de ella- Guía Práctica. 2020. https://www.ilo.org/wcmsp5/groups/public/---ed_protect/---protrav/--travail/documents/publication/wcms_758007.pdf
} 
Bajo este prisma, conviene tener presente que ya el Convenio $\mathrm{n}^{\circ}$. 132 OIT, en relación con las vacaciones anuales ${ }^{80}$, se refería al derecho al descanso de "todo trabajador". Ciertamente el tiempo de trabajo flexible puede contribuir a una mejor compatibilidad de la vida privada y la profesional, sin embargo, no parece muy acertado de cara al óptimo descanso y "desconexión” de las responsabilidades laborales, tal y como contempla la normativa internacional.

Por su parte, la Directiva 2003/88/CE, sobre la regulación específica del tiempo de trabajo y las consecuencias jurídicas del incumplimiento de los tiempos de descanso, en su interpretación por el TJUE reconoce, que el empresario tiene el deber de garantizar que el trabajador, en cualquier caso, o con cualquier tipo de relación laboral, debe atenderse su derecho al descanso efectivo ${ }^{81}$, aunque prescinde de una definición concreta de qué debe entenderse por tal "descanso efectivo". Tampoco lo recoge la Carta de Derechos Fundamentales de la Unión Europea, si bien, tal vez por ser más reciente cronológicamente, en su art. 31.2, especifica más al referirse al derecho a "períodos de descanso diarios y semanales" 82 .

En el ámbito interno, es conocido que el texto constitucional, dentro de los principios rectores de la política social y económica (art. 40.2 CE), encomienda a los poderes públicos garantizar "el descanso necesario, mediante la limitación de la jornada laboral, las vacaciones periódicas retribuidas y la promoción de centros adecuados". Atendiendo a esta previsión constitucional, la LPRL contempla varios preceptos que imponen al empresario la obligación de establecer medidas de prevención relacionadas con el principio de adaptación del trabajo a la persona y no al contrario, lo que supone el deber de planificar y delimitar medidas concretas para garantizar la seguridad y salud en todos los aspectos relacionados con el trabajo ${ }^{83}$. Incluso algunos autores lo conectan con la necesidad de ofrecer al trabajador una formación preventiva en el uso razonable de las tecnológicas digitales ${ }^{84}$.

Sin embargo, en nuestro país, la doctrina mayoritaria se ha manifestado bastante escéptica con la verdadera necesidad de regular ex novo un derecho concreto que garantice el clásico derecho al descanso. De hecho, se mantienen posturas ambiguas en tanto a la necesidad de adaptar el ordenamiento jurídico preexistente a las posibilidades

\footnotetext{
${ }^{80} \mathrm{C} 132$ - Convenio sobre las vacaciones pagadas (revisado), 1970 (núm. 132); Convenio relativo a las vacaciones anuales pagadas (revisado en 1970); (entrada en vigor: 30 junio 1973); adopción: Ginebra, 54a reunión cit. (24 junio 1970).

${ }^{81}$ Por todas, STJUE de 7 de septiembre de 2006, asunto Comisión frente Reino Unido (C-484/04).

${ }^{82}$ Carta de los Derechos Fundamentales de la Unión Europea (2010/C 83/02). DOUE núm. 83, de 30 de marzo de 2010. Texto revisado, por Acuerdo Internacional de 12 de diciembre de 2007 (Ref. DOUE-Z2012-70012).

${ }^{83}$ Art. 14 y art. 16, Ley 31/1995, de 8 de noviembre, de Prevención de Riesgos Laborales, BOE de 10 de noviembre de 1995. Así lo ha interpretado el TS, por todas, STS 16 de febrero de 2016, rec, $\mathrm{n}^{\circ}$. 250/2014.

${ }^{84}$ Se apoya para esto en la referencia del art. 29 LPRL, sobre los cambios organizativos y el deber de "colaboración" del trabajador, supeditado a las capacidades y a la formación del trabajador, pero también, a las órdenes recibidas IGARTUA MIRÓ, $\mathrm{M}^{\mathrm{a}}$. Teresa, Ordenación flexible del tiempo de trabajo..., op. cit., p. 364. En la misma línea, sobre críticas a la regulación francesa del derecho a la desconexión, CIALTI, Pierre H., "El derecho a la desconexión en Francia: ¿más allá de lo que parece?”, Temas Laborales, nº 137, 2017, pp. 172-180.
} 
tecnológicas que permiten una extrema flexibilidad horaria. Bien porque se considera que se trata de aplicar las mismas reglas limitativas del exceso de tiempo de trabajo -jornada y disponibilidad horaria- existentes en la actualidad, pero con una interpretación extensiva teniendo en cuenta la desaparición del centro de trabajo físico como unidad de referencia $(\text { art. } 1.5 \mathrm{ET})^{85}$. O bien, se estima que, al tratarse de un derecho de titularidad individual, es su propio titular quien puede disponer de su ejercicio, es decir, el trabajador será quién podrá graduar y pactar como organiza su propia "conectividad" 86 , aunque esto sería dudoso si se tiene en cuenta el carácter de derecho necesario y la relación con la protección a la seguridad y salud en el trabajo que podría alcanzar esta materia ${ }^{87}$.

Sea como fuere, la digitalización de la organización empresarial exige que una normativa estricta que delimite los tiempos de trabajo y descanso, así como respecto de las responsabilidades de conciliación entre las obligaciones familiares y laborales. Como reconoce la Comisión Europea en la interpretación sobre la Directiva 2003/88 ${ }^{88}$, conviene hacer frente y actualizar los desafíos de cambiar la organización del trabajo, teniendo en cuenta que la digitalización conlleva una mayor fragmentación del trabajo, tanto en la ubicación como en el tiempo de disposición. Es decir, "las nuevas formas de empleo, como el trabajo móvil basado en las TIC y el trabajo por carteras, ofrecen ventajas significativas para que los empleados organicen su tiempo de trabajo de forma flexible, aunque, al mismo tiempo, también implican peligros como un aumento del tiempo de trabajo", por lo que se requieren medidas concretas que garanticen unas condiciones de trabajo "saludable" 89 y con derechos laborales mínimos para todos los trabajadores. También la Estrategia Europea de la Salud y Seguridad en el Trabajo 2014-2020, se refiere a la necesidad de hacer frente a esos nuevos riesgos laborales ${ }^{90}$.

Siguiendo estas indicaciones, existen recientes experiencias legislativas de ordenamientos nacionales $^{91} \mathrm{y}$ de multinacionales que han empezado a construir

${ }^{85}$ MOLINA NAVARRETE, Cristóbal, "Jornada laboral y tecnologías de la infocomunicación: 'la desconexión digital', garantía del derecho al descanso", op. cit., pp. 258-261. Con un interesante análisis de la STS 379/2017, de 28 de abril, en relación con el asunto TYCO.

${ }^{86}$ ALEMÁN PÁEZ, Francisco, "El derecho a la desconexión digital. Una aproximación conceptual, crítica y contextualizada al hilo de la 'Loi Travail n'. 2016-1088', Revista Trabajo y Derecho, n $^{\circ}$. 30, 2017, p. 18.

${ }^{87}$ IGARTUA MIRÓ, Ma . Teresa, Ordenación flexible del tiempo de trabajo..., op. cit., p. 363. La autora se muestra partidaria del carácter garantista de la norma francesa sobre el derecho a la desconexión, aunque lleve este derecho a la negociación colectiva como vía de regulación principal.

${ }^{88}$ Comunicación interpretativa sobre la Directiva 2003/88/CE del Parlamento Europeo y del Consejo, relativa a determinados aspectos de la ordenación del tiempo de trabajo (2017/C 165/01), de 24 de mayo de 2017.

${ }^{89}$ Documento de trabajo de los servicios de la Comisión, Programa de adecuación y eficacia de la reglamentación (REFIT) y las diez prioridades de la Comisión que acompaña al documento Comunicación de la Comisión al Parlamento Europeo, al Consejo, al Comité Económico y Social Europeo y al Comité de las Regiones, Programa de Trabajo de la Comisión para 2017, Realizar una Europa que proteja, capacite y vele por la seguridad, SWD/2016/0400 final, de 4 de octubre de 2017.

${ }^{90}$ Communication from the commission to the European Parliament, the Council, the European Economic and Social Committee and the Committee of the Regions on an EU Strategic Framework on Health and Safety at Work 2014-2020, Bruselas, 6 de junio de 2014, COM (2014) 332 final.

${ }^{91} \mathrm{Al}$ respecto han proliferado estudios en nuestra doctrina tanto sobre la norma francesa al respecto, como sobre la italiana o el proyecto legislativo alemán sobre el estrés laboral y la conectividad, ya del año 2014. Incluso cabe destacar como la globalización ha hecho que este "nuevo" derecho también se haya previsto 
acuerdos $^{92}$ en torno a la regulación y reconocimiento del denominado "derecho a la desconexión tecnológica". Finalmente también en nuestro ordenamiento, con la adaptación de la normativa al Reglamento Europeo de Protección de Datos ${ }^{93}$, se ha producido el reconocimiento expreso del renombrado derecho desde el 7 de diciembre de 2018, fecha de la entrada en vigor de la Ley Orgánica de Protección de Datos Personales y Garantía de Derechos Digitales ${ }^{94}$.

En efecto, se trata de una norma con un importante Título X que bajo la rúbrica "garantía de los derechos digitales" recoge una serie de medidas que suponen importantes modificaciones en el ET, pero también en el EBEP ${ }^{95}$. Además, el RD-Ley 28/2020, en su art. 18, también se reconoce el derecho a la desconexión digital en los términos del art. 88 LOPDP.

La "estrella mediática"96 de esta norma se recoge en la Disposición Final $13^{\text {a }}$ que introduce un nuevo art. 20 bis en el ET de cuyo tenor literal se desprende el reconocimiento del derecho de los trabajadores "a la desconexión digital", junto a la "intimidad en el uso de los dispositivos digitales puestos a su disposición por el empleador (...) y uso de dispositivos de viodeovigilancia y geolocalización" que se ejercerá según "la legislación vigente en materia de protección de datos personales y garantía de los derechos digitales".

Si bien se trata de una normativa innovadora que pretende actualizar la regulación de las relaciones laborales a la realidad, presenta ciertas carencias que difuminan estas buenas expectativas. Por un lado, respecto del precepto elegido para ser introducido, el art. 20 ET, es decir, en relación directa con los límites del poder directivo empresarial, por

en normas de países asiáticos cuyo derecho al descanso se concibe de manera muy diferente -incluso opuesta- a como se hace desde los ordenamientos europeos. Al respecto, vide MOLINA NAVARRETE, Cristóbal, "Jornada laboral y tecnologías de la infocomunicación: 'la desconexión digital', garantía del derecho al descanso", op. cit.; ARANGÜREZ VALENZUELA, Lucía, "El impacto de las tecnologías de la información y de la comunicación en el tiempo de trabajo: una especial referencia a la desconexión digital", en AA. VV., La adaptación del ordenamiento español a la jurisprudencia social del Tribunal de Justicia, Cinca, Madrid, 2018, pp. 402-405.

${ }^{92}$ Es el caso de la empresa Volkswagen, respecto a la hora límite para recibir emails del trabajo; o la empresa IBM que ha dejado de controlar los días de vacaciones de sus empleados al considerar que es mejor dejarles libertad para que ellos mismo se organicen. Sobre estos casos fuera de España, USHAKOVA, Tatsiana, "De la conciliación a la desconexión tecnológica. Apuntes para el debate", op. cit. Sobre el convenio colectivo de la empresa AXA, la primera que introdujo estas cláusulas en nuestro país, estupendo estudio de TALÉNS VISCOTI, Eduardo, "La desconexión digital en el ámbito laboral: un deber empresarial y una nueva oportunidad de cambio para la negociación colectiva", Revista de Información Laboral, $\mathrm{n}^{\circ} .4$, 2018, pp. 204-206.

${ }^{93}$ Reglamento (UE) 2016/679 del Parlamento Europeo y del Consejo de 27 de abril de 2016 relativo a la protección de las personas físicas en lo que respecta al tratamiento de datos personales y a la libre circulación de estos datos y por el que se deroga la Directiva 95/46/CE (Reglamento general de protección de datos). DOUE de 4 de mayo de 2016, con entrada en vigor en los EEMM en mayo de 2018.

${ }^{94}$ LO 3/2018, de 5 de diciembre, de Protección de Datos Personales y Garantía de Derechos Digitales. BOE de 6 de diciembre de 2018. Entra en vigor el día 7 de diciembre, según la DF 16a .

95 Al respecto, como siempre, una análisis ortodoxo y exhaustivo, en el Blog del Prof. ROJO TORRECILLA, Eduardo, "Los derechos digitales laborales en la Ley Orgánica 3/2018, de 5 de diciembre, de Protección de datos Personales y garantías de los derechos digitales. Notas al título X", http://www.eduardorojotorrecilla.es/2018/12/los-derechos-digitales-laborales-en-la.html.

${ }^{96}$ Op. cit. 
entender que éste queda sujeto a esa limitación en el tiempo de trabajo. Sin embargo, debe compartirse la crítica de la doctrina sobre la clamorosa ausencia de la incorporación de este nuevo derecho al elenco del art. $4 \mathrm{ET}^{97}$, pues debería especificarse su carácter individual, además del colectivo. Se ha desperdiciado la posibilidad de otorgarle la primacía de los derechos fundamentales del trabajador a su intimidad ${ }^{98} \mathrm{y}$, a la vez se desprecia la consideración individualista del art. 18.3 CE sobre la capacidad del trabajador para gestionar sus datos, en lugar de entregarle ese poder al empresario, como si se tratase de un instrumento de gestión empresarial más ${ }^{99}$. Y, sobre el propio contenido, se echan en falta las referencias a los derechos de conciliación, que sí aparecen entorno a los empleados públicos [art. 14, leta j) bis EBEP] ${ }^{100}$.

Es cierto que el art. 88 LOPDP señala que el contenido esencial del derecho de desconexión digital es "garantizar fuera del tiempo de trabajo legal o convencionalmente establecido, el respeto de su tiempo de descanso, permisos y vacaciones, así como de su intimidad personal y familiar". Por lo tanto, más allá de los límites temporales y espaciales que se derivarán para la empresa, a través de la regulación de este derecho tendrá que preservarse la intimidad y la conciliación de la vida personal con el trabajo. Y, para alcanzar ese objetivo, el papel de la negociación colectiva tendrá un papel protagonista, hasta el punto que el art. 91 LOPDP conecta, de forma directa, el ejercicio de estos derechos digitales con "lo acordado entre la empresa y los representantes de los trabajadores".

Ahora bien, ese importante papel que se otorga a la negociación colectiva, deviene invisible, prácticamente, en relación con las situaciones de especial riesgo, como son las derivadas del trabajo a distancia y la conocida afección de la "fatiga informática". Sobre estos casos, el art. 88 LOPDP se remite al desarrollo del tema por una "política interna" en la que los representantes de los trabajadores se limitan a ser consultados, pero será el empresario el que unilateralmente implemente esas "acciones de formación y de sensibilización del personal sobre un uso razonable de las herramientas tecnológicas que evite el riesgo de la fatiga informática". De esta manera el empleador será el que determine el verdadero alcance de los derechos digitales de estos trabajadores por lo que

\footnotetext{
97 Con la calificación de "decepcionante", un estudio en profundidad y centrado en el papel de la negociación colectiva al respecto de los derechos digitales en el ámbito laboral, BAYLOS GRAU, Antonio, "Una nota sobre el papel de la negociación colectiva en la configuración de los derechos derivados de la Ley Protección de datos Personales y garantías de los derechos digitales", Revista de Derecho Social editorial, $\mathrm{n}^{\mathrm{o}}$ 84, 2019, pp. 5-7. Un adelanto más sintético en el Blog. del mismo Profesor, http://baylos.blogspot.com/2018/11/la-garantia-de-los-derechos-digitales.html;

98 GOÑI SEIN, José Luis, "Nuevas tecnologías digitales, poderes empresariales y derechos de los trabajadores. Análisis desde la perspectiva del Reglamento de Protección de Datos de 2016", Revista de Derecho Social, n. 78, 2017, pp. 25-29.

${ }^{99}$ MIÑARRO YANINI, Margarita, "Impacto del Reglamento de Protección de Datos en las relaciones laborales: un -pretendido- cambio cultural", CEF. Revista de Trabajo y Seguridad Social, nº. 423, 2018, p.6.

${ }^{100}$ Así lo señala en la entrada correspondiente de su blog el Prof. ROJO TORRECILLA, Eduardo, "Los derechos digitales laborales en la Ley Orgánica 3/2018...”, op. cit.
} 
se ha afirmado por la doctrina que se ha "neutralizado" el avance que, en este campo, podría haber supuesto la alabada norma ${ }^{101}$.

En torno a la duda que se puede presentar sobre la posibilidad de interponer una reclamación individual por un trabajador como derecho subjetivo a la desconexión digital, cuando no exista un pacto colectivo -estatutario o extraestautario- que recoja esta posibilidad, nada debería impedir que se acuda a un pacto individual para su regulación y, como tal, pueda seguir la vía procesal oportuna ${ }^{102}$. Es decir, se trata de una oportunidad que tienen la empresa y el trabajador de adaptar su jornada, pero que va mucho más allá de las clásicas premisas de la reducción de jornada o cambio de turno, típicos problemas suscitados sobre los derechos de conciliación, en el marco del art. 34.8.2 ET.

Analizada esta nueva - o no tan nueva- forma de prestar el trabajo y su relación con los derechos de conciliación y de corresponsabilidad, cabe ahora abordar la reducción del tiempo de trabajo como otra de las modalidades clásicas en las que se han amparado los ordenamientos jurídicos internos y europeos para facilitar la compatibilidad entre los tiempos vitales de las personas trabajadoras.

\section{La disfuncionalidad del trabajo a tiempo parcial como medida de conciliación}

En sus orígenes el trabajo a tiempo parcial se configuró como el instrumento más efectivo para conciliar la vida familiar y laboral. No obstante, la doctrina pronto puso de manifiesto que se trata de una práctica alejada de la esencia de la conciliación, por sus perversas consecuencias sobre quien lo disfruta ${ }^{103}$. A continuación, se da una perspectiva del impacto tan negativo que conlleva sobre las carreras profesionales, como se desprende de su análisis por la jurisprudencia comunitaria, sobre todo, en relación con la normativa española.

El prototipo de protección del Sistema de Seguridad Social está articulado en base a un trabajador -en masculino- indefinido y a tiempo completo, sin interrupciones y con largos y elevados niveles de contributividad. De manera que la mujer, en muchos casos, no va a encontrar cobijo en esta concepción de protección social, ya que es habitual que cuente con lagunas o interrupciones en su carrera de cotización por la asunción de las cargas familiares. También es frecuente que reduzca su jornada laboral o directamente que su contrato sea a tiempo parcial, con la finalidad de conciliar sus obligaciones laborales y familiares. En realidad, este tipo de empleo no cuestiona el rol de género, sino que es una modalidad de trabajo ad hoc ${ }^{104}$. Todas estas situaciones, unidas a la discriminación

\footnotetext{
${ }^{101}$ BAYLOS GRAU, Antonio, "Una nota sobre el papel de la negociación colectiva en la configuración de los derechos derivados de la Ley Protección de datos Personales y garantías de los derechos digitales", Revista de Derecho Social-editorial-, op. cit.

${ }^{102}$ RODRÍGUEZ RODRÍGUEZ, Emma, "El derecho a la negociación colectiva del trabajador autónomo en el contexto de la nueva economía digital", Temas Laborales, nº 151, 2020, pp. 139 y ss.

${ }^{103}$ CABEZA PEREIRO, Jaime, El trabajo a tiempo parcial y las debilidades del modelo español, Bomarzo, Albacete, 2013.

${ }^{104}$ CARACCIOLO DI TORELLA, Eugenia y MASSELOT Annik, Reconciling Work and Family Life in EU Law and Policy, Palgrave- Macmillan, London, 2010, p. 118 y ss.
} 
salarial y a la falta de promoción profesional, conllevan repercusiones directas sobre la cuantía y el acceso a las prestaciones del sistema de Seguridad Social.

Estos efectos perversos vinculados al género de la persona trabajadora han sido apreciados por la OIT en varios instrumentos jurídicos. Destaca el Convenio no 111 que protege la igualdad de oportunidades o de trato en el empleo y admite que se adopten medidas de acción positiva a favor del colectivo desfavorecido mientras dure la situación discriminatoria. Más específicos son el Convenio no $\mathrm{n}^{\circ} .156$ y su Recomendación $\mathrm{n}^{\circ}$. 165, sobre la igualdad de oportunidades y de trato entre trabajadores y trabajadoras con responsabilidades familiares. Por otra parte, el derecho a una protección social mínima se recoge en el Convenio $n^{\circ} .102$ y el Convenio $n^{\circ} .175$ OIT y su correlativa Recomendación $\mathrm{n}^{\mathrm{o}}$. 182, promocionan el trabajo a tiempo parcial como medio para fomentar el empleo y resaltan su equivalencia respecto de las condiciones de trabajo con los trabajadores a tiempo completo. Sin embargo, ambos estas normas ignoran completamente el principio de igualdad y su relación con el ejercicio de los derechos de conciliación.

En la misma línea, el art. 157.3 TFUE se refiere a la adopción de medidas a nivel europeo destinadas a garantizar la igualdad de trato en asuntos de empleo y ocupación ${ }^{105}$, lo que se relaciona directamente con la igualdad por razón de sexo, así como, con las medidas de conciliación de la vida personal, familiar y laboral. También la Directiva 2006/54/CE, relativa a la aplicación del principio de igualdad de oportunidades e igualdad de trato entre hombres y mujeres en asuntos de empleo y ocupación (refundición), en sus consideraciones preliminares, se refiere al principio de igualdad entre hombres y mujeres como fundamental en el Derecho europeo. Incide en la igualdad de retribución, en la que se incluyen todas las prestaciones o indemnizaciones con cargo a la propia empresa (STJUE de 17 de mayo de 1990, asunto C-262/88, Barber/Guardian Royal Exchange AssuranceGroup) y los "regímenes profesionales de seguridad social" (STJUE de 22 de noviembre de 2012, C-385/11, asunto Isabel Elbal Moreno/INSS y TGSS). Además, define "acción positiva" con objeto de garantizar en la práctica la plena igualdad entre hombres y mujeres en la vida laboral (STJUE de 25 de octubre de 1988, C-312-86, asunto Comisión contra Francia). En todo caso, debe interpretarse de manera restrictiva, buscado una finalidad legítima y el respeto al principio de proporcionalidad, como exige el TJUE "que no se traspasen los límites de lo que es adecuado y necesario para la consecución del objetivo que se persigue con la excepción" (STJUE de 11 de noviembre de 1997, asunto C-409/95, Hellmut Marschall- Land Nordrhein-Westfalen).

Esta regulación sobre la igualdad por razón de sexo en el empleo se completa incidiendo en aspectos más específicos, como la Directiva 79/7/CEE, relativa a la aplicación progresiva del principio de igualdad de trato entre hombres y mujeres en materia de seguridad social, sobre la materia de seguridad social y el Acuerdo Marco sobre el trabajo a tiempo parcial, recogido por la Directiva 97/81/CE.

Por su parte, la Directiva 2010/18/UE en la Cláusula 1.3 incluye expresamente en su ámbito de aplicación las relaciones a tiempo parcial, temporales o a través de empresas

105 También la Carta de los Derechos Fundamentales de la Unión Europea (2000/C 364/01), arts. 20 y 21. 
de trabajo temporal. No obstante, excluye de su ámbito de protección las reducciones de jornada, en el caso de que se trate de un trabajo a tiempo parcial, al igual que el cómputo de la antigüedad necesaria que pueden establecer los Estados miembros para poder disfrutar del permiso parental. Es más, la Cláusula 5.5 determina la competencia de los Estados miembro respecto de "los derechos a las prestaciones de Seguridad Social". Tampoco resulta concreta cuando reconoce al trabajador reincorporado, tras el disfrute de un permiso parental, la posibilidad de pedir cambios en sus horarios (Cláusula $6^{\mathrm{a}}$ ). Todo esto causa una gran desprotección jurídica sobre las personas que ejercen sus derechos de conciliación acogiéndose, por ejemplo, al trabajo a tiempo parcial, siendo mayoritariamente mujeres las que se encuentran en esta situación.

Pues bien, para eliminar o reducir esa parcialidad no deseada, a la que se ven abocadas muchos trabajadores como única alternativa para conciliar los horarios laborales y los familiares, se viene reclamando una actualización o renovación de las fórmulas de trabajo flexible, así como su disfrute de manera más equitativa106. En esta línea, la nueva Directiva UE 2019/1158, amplía las fórmulas de trabajo flexible -modelo y horario-, para los trabajadores que se reincorporen de un permiso parental. De hecho, adopta una nueva formulación relacionada con el denominado "trabajo a distancia". Sin embargo, la problemática interpretativa persiste en tanto que la normativa sobre tiempo de trabajo se ha articulado al margen de la conciliación y, de manera concreta, el trabajo a tiempo parcial y sus repercusiones sobre la protección social lo que incrementan la separación de roles y entorpecen las posibilidades reales de la plena incorporación de la mujer al mercado de trabajo.

El TJUE se ha ocupado en múltiples ocasiones de la interpretación normativa del principio de igualdad entre hombres y mujeres en materia de Seguridad Social, sobre todo en relación con asuntos referidos a la discriminación indirecta. La reserva de competencias de los Estados miembro en política social ha supuesto un freno para el Tribunal que ha justificado en la aplicación de esas normas el efecto adverso por razón de sexo (STJUE de 11 de julio de 1987, C-30/85, asunto Teiling, sobre las diferencias en la prestación de invalidez), salvo contadas excepciones, por ejemplo, STJUE de 20 de octubre de 2011, C-123/10, asunto Brachner que considera discriminatoria una disposición nacional que implique excluir de un incremento de la pensión a un mayor porcentaje de mujeres que de hombres.

Esta postura restrictiva de la jurisprudencia europea se refuerza respecto del trabajo a tiempo parcial, en particular, cuando se trata de prestaciones de Seguridad Social públicas cuya contingencia acontece o deriva de esa modalidad contractual. Son significativas STJUE de 14 de diciembre de 1995, C- 317/93, asunto Nolte, sobre la exclusión del derecho de acceso a una pensión de invalidez para trabajadores que no alcancen el $15 \%$ de la jornada laboral; también, STJUE de 13 de diciembre de 1994, C-297/93, asunto

106Comisión Europea, Una iniciativa para promover la conciliación de la vida familiar y la vida profesional de progenitores y cuidadores, Comunicación de la Comisión al Parlamento Europeo, al Consejo, al Comité Económico y Social Europeo y al Comité de las Regiones. Bruselas, 26 de abril de 2017. COM (2017) 252 final. 
Grau-Hupka, y STJUE de 16 de julio de 2009, C- 537/07, asunto Gómez Limón, en ambos casos los permisos parentales a tiempo parcial perjudican las prestaciones de jubilación parcial y de incapacidad permanente, respectivamente, que con posterioridad se solicitaron por las trabajadoras.

Si bien, existen pronunciamientos en los que el Tribunal no ha estimado la justificación del trato peyorativo en base a los criterios objetivos alegados, como STJUE de 13 de diciembre de 1989, C-102/88, asunto Ruzius Wilbrink, que considera discriminatoria, por afectar más a mujeres que a hombres, la norma nacional que excluía a los trabajadores a tiempo parcial de acceso a una prestación para personas incapacitadas, en función de la cuantía de ingresos anteriores. Resultan muy significativos los pronunciamientos STJUE de 10 de junio de 2010, C-395/08 y C-396/08, asunto Bruno y Pettini, así como STJUE de 22 de noviembre de 2012, C- 385/11, asunto Elbal Moreno, que consideran que existe discriminación indirecta por razón de sexo en el caso de que el método para calcular la carencia necesaria para acceder a una prestación resulte imposible de cumplir por los trabajadores a tiempo parcial, mayoritariamente mujeres ${ }^{107}$.

El año pasado, el TJUE, de nuevo en relación con la regulación de nuestro país, ha entrado a resolver la cuestión prejudicial presentada por un juez nacional que se cuestionaba el carácter eventualmente discriminatorio por razón de sexo que puede conllevar el método de cálculo de una determinada pensión, con respecto a los trabajadores que hayan trabajado y cotizado a tiempo parcial frente a los que lo hayan hecho a tiempo completo. En el supuesto concreto, STJUE de 8 de mayo de 2019 (C-161/2018), asunto Violeta Villar Láiz e INSS y TGSS, se trataba de una pensión de jubilación que se veía considerablemente disminuida por aplicar los coeficientes de parcialidad y el principio pro rata temporis ${ }^{108}$.

En concreto se cuestiona la existencia de la discriminación indirecta por razón de sexo en relación con la Directiva 79/7/CEE, en concreto respecto del art. 4. El órgano remitente afirma que la repercusión jurídica de ese efecto negativo recae especialmente sobre mujeres, dada la feminización del trabajo a tiempo parcial. Al mismo tiempo, duda sobre la existencia de una justificación objetiva para esa diferencia legal entre el trabajo a tiempo completo y a tiempo parcial, aun atendiendo al principio de contributividad que informa el Sistema Público de pensiones. Concluye que no existe ningún criterio de proporcionalidad, desde la perspectiva de la contribución efectuada por la trabajadora afectada porque, según la norma, directamente se tendrá en cuenta el coeficiente de parcialidad correspondiente al contrato por el que cotiza.

107 FERRADANS CARAMÉS, Carmen, "Impacto de la doctrina del Tribunal de Justicia de la Unión Europea sobre la aplicación del principio de igualdad y no discriminación a los trabajadores a tiempo parcial", Tutela y promoción de la plena integración de la mujer en el trabajo. Libro homenaje a la profesora Teresa Pérez del Río, CRUZ VILLALÓN, Jesús, GARRIDO PÉREZ, Eva y FERRADANS CARAMÉS, Carmen (coords.), Consejo Andaluz de Relaciones Laborales, 2015, pp. 259 y ss.

108 GALA DURÁN, Carolina, "La nueva forma de cálculo de la pensión de jubilación de los trabajadores a tiempo parcial: Comentario a la STJUE de 8 de mayo de 2019 (asunto Villar Láiz) y a la STC 91/2019, de 3 de julio", La administración práctica: enciclopedia de administración municipal, n¹0, 2019, pp.8796. 
Por su parte, el Gobierno español sostiene que la normativa pretende garantizar el sistema público de pensiones justo, equilibrado y solidario asegurando la sostenibilidad y el equilibrio financiero del régimen de la Seguridad Social, según el art. 41 de la Constitución española. Se basa en el principio de contributividad, de manera que la protección ofrecida por ese sistema nunca puede superar la contribución previamente aportada al mismo, así pues, la pensión será proporcional al abono de las cotizaciones inmediatamente posteriores al trabajo a tiempo parcial, que son proporcionalmente inferiores. Ahora bien, como le recuerda el Tribunal, por esos mismos motivos, no está justificada la diferencia, pues este método de cálculo perjudica desproporcionadamente a la trabajadora, con respecto a las cotizaciones abonadas por la interesada a lo largo de toda su carrera profesional. $\mathrm{E}$ insiste en que las estadísticas demuestran que esta normativa perjudica particularmente a las trabajadoras femeninas al constituir el $75 \%$ de los trabajadores a tiempo parcial (apartado 42).

En definitiva, el Tribunal sí estimó que el sistema de cálculo de la norma nacional era contrario al art. 4.1 Directiva 7/79/CEE y aprecia discriminación indirecta por razón de sexo. Este pronunciamiento está en la línea de otros que han dado lugar a importantes modificaciones legislativas, como fue la Ley 1/2014, de 28 de febrero para la protección de los trabajadores a tiempo parcial y otras medidas urgentes en el orden económico y social, que trae causa del asunto Elbal Moreno -y las STC 61/2013, de 14 de marzo, así como las siguientes SSTC 71/2013 y 72/2013, de 8 de abril, y 116/2013 y 117/2013, de mayo-. en el que el Tribunal se mostró contundente en su crítica sobre la ausencia de justificación de la medida nacional que se discutía, en base al mantenimiento y viabilidad del Sistema público y contributivo de Seguridad Social ${ }^{109}$.

En fin, puede afirmarse que las discriminaciones indirectas por razón de sexo inciden sobre las trabajadoras a tiempo parcial porque sufren las consecuencias de unos sistemas de protección social que las perjudican por ejercer sus derechos de conciliación. Por lo tanto, para que a las tradicionales cuidadoras del hogar familiar les merezca la pena acceder al mercado de trabajo es necesario que los trabajos atípicos a los que tienen acceso no resulten desventajosos. De lo contrario, el trabajo a tiempo parcial continuará siendo una fuente de discriminación indirecta por razón de sexo, lo que, a su vez, agravará los problemas de conciliación y hará inalcanzable una verdadera corresponsabilidad.

\section{Reflexiones finales: el reconocimiento del trabajo de los cuidados}

Es necesario que la organización del tiempo de trabajo se lleve a cabo con perspectiva de género, es decir, avanzar de una vez por todas en la conciliación de la vida privada y la vida laboral. La vía óptima hacia el trabajo de cuidados decente es factible, pero debe apoyarse en políticas transformadoras y en el trabajo decente. En concreto, en asegurar

\footnotetext{
${ }^{109}$ Fundamento $\mathrm{n}^{\mathrm{o}}$. 35: “(...) en estas circunstancias, la exclusión de los trabajadores a tiempo parcial de toda posibilidad de obtener una pensión de jubilación constituya una medida efectivamente necesaria para alcanzar el objetivo de salvaguardar el sistema de seguridad social de tipo contributivo, al que se refieren el INSS y el Gobierno español, y que ninguna otra medida menos gravosa para esos mismos trabajadores permita alcanzar ese objetivo".
} 
un futuro del trabajo que se apoye en la justicia social y promueva la igualdad de género para todos.

En el año 2050 en España se prevé que más del 58\% de la población sea mayor de 64 años, lo que agrava considerablemente las probabilidades de ser personas dependientes ${ }^{110}$, lo que supone una necesidad exponencial de trabajadores dedicados a estas tareas de cuidado, a la vez que requerirá de una fuerte inversión pública. Su aplicación exigirá duplicar la inversión en la economía del cuidado, lo que podría conducir a un total de 475 millones de empleos de aquí a 2030, es decir 269 millones de nuevos empleos, al respecto ${ }^{111}$.

La OIT ha situado el trabajo de cuidados en el centro de las iniciativas para el centenario relativas a las mujeres en el trabajo y al futuro del trabajo. La consecución de la igualdad de género en el trabajo también es una prioridad urgente como consecuencia de la adopción del ODS 5, que tiene por objeto reconocer y valorar el trabajo de cuidados no remunerado "mediante la prestación de servicios públicos, la provisión de infraestructuras y la formulación de políticas de protección social" (meta 5.4). Este compromiso mundial con la igualdad de género ha ido acompañado de un reconocimiento del papel que desempeña el Programa de Trabajo Decente para transformar el planeta, erradicando la pobreza extrema y mitigando las desigualdades. Este compromiso sobre la igualdad en el trabajo ha sido reafirmado por el ODS 8 sobre el empleo pleno y productivo y el trabajo decente para todos los hombres y mujeres.

Vivimos en la era de la comunicación, de las TICS y de la digitalización del mercado laboral. Todos estos atributos deben conllevar un mercado laboral más inclusivo y aprovecharse para avanzar hacia una mayor igualdad en las condiciones laborales de todas las personas trabajadoras, ahondando en el respeto "a los derechos humanos y los derechos fundamentales y los valores de la Unión", tal y como ha proclamado recientemente el Parlamento Europeo ${ }^{112}$. La discriminación algorítmica, en la que se encuentra la pervivencia de la discriminación indirecta, puede ser atajada en su origen con instrumentos jurídicos correctores que se adelanten a esos estereotipos sobre los que se definen ${ }^{113}$.

El trabajo de los cuidados tradicionalmente ha quedado al margen de los sistemas de protección social que dispensan los ordenamientos jurídicos al trabajo "productivo". Resulta imprescindible que el Estado del Bienestar incluya dentro de sus prestaciones el

\footnotetext{
${ }^{110}$ Ministerio de Sanidad, Servicios Sociales e Igualdad, IMSERSO, Informe 2012, Las personas mayores en España. http://envejecimiento.csic.es/documentos/documentos/imserso-infoppmm2012-10-2014.pdf

${ }^{111}$ OIT, El trabajo de cuidados y los trabajadores del cuidado para un futuro con trabajo decente, 2018. https://www.ilo.org/wcmsp5/groups/public/---dgreports/---dcomm/--publ/documents/publication/wcms_633168.pdf

${ }^{112}$ Resolución del Parlamento Europeo, de 20 de octubre de 2020, con recomendaciones destinadas a la Comisión sobre un marco de los aspectos éticos de la inteligencia artificial, la robótica y las tecnologías conexas (2020/2012(INL),

https://www.europarl.europa.eu/doceo/document/TA-9-2020-0275_ES.html\#top

113 Excelente análisis con estudio de derecho comparado, SÁENZ LARA, Carmen, "Algoritmos y discriminación en el empleo: un reto para la normativa antidiscriminatoria", Revista Española de Derecho del Trabajo, $\mathrm{n}^{\circ}$. 232, junio, 2020.
} 
cuidado cotidiano, no sólo el de dependientes o menores, atendiendo a sus normativas nacionales, sino también la universalización del social care $^{114}$ como una exigencia impuesta por el Programa de Trabajo Decente.

La Agenda 2030 y el Programa de Trabajo Decente confluyen para definir la vía óptima hacia el trabajo de cuidados decente basada en la justicia social. Así pues, realiza un llamamiento para que se presten cuidados de buena calidad, que beneficien tanto a las cuidadoras y cuidadores no remunerados como a las personas a quienes van destinados los cuidados, y se proporcione trabajo decente a los trabajadores y trabajadoras del cuidado. Ha de incidirse en políticas de cuidado, macroeconómicas, de protección social, laborales y migratorias.

Las medidas necesarias para lograr la vía óptima hacia el trabajo de cuidados decente en el marco del trabajo de cuidados decente se articulan sobre reconocer, reducir $y$ redistribuir el trabajo de cuidados no remunerado; re-compensar el trabajo de cuidados remunerado, promoviendo más trabajo y el trabajo decente para los trabajadores y trabajadoras del cuidado, y garantizar la representación, el diálogo social y la negociación colectiva de las trabajadoras y trabajadores del cuidado ${ }^{115}$. Cada grupo de recomendaciones se corresponde con un conjunto de acciones encaminadas a contribuir al avance de la vía óptima hacia el trabajo de cuidados decente con un enfoque sensible a las cuestiones de género y basado en los derechos humanos, con el que se busca mitigar las desigualdades relacionadas con los cuidados ${ }^{116}$.

La crisis de la COVID-19 ha puesto de manifiesto la urgencia de sacar definitivamente de la invisibilidad la tarea de los cuidados y poner en marcha políticas públicas que los aborden como derechos. Los cuidados no pueden seguir invisibles y recayendo en el voluntarismo de las estructuras familiares. En concreto, debe avanzarse en dotar de derechos reales a estas trabajadoras y reconocerse esa tarea de cuidados para evitar las desigualdades de las que son víctimas a la hora del acceso a pensiones, por ejemplo, al menos hasta que exista un servicio público y universal de calidad. Las tareas de los cuidados que se realizan en la actualidad en el mercado laboral, se producen bajo situaciones de extrema precariedad y nulo reconocimiento social, principalmente por mujeres, en su mayoría migrantes y a menudo, en condiciones cercanas a la explotación laboral.

\footnotetext{
${ }^{114} \mathrm{Al}$ respecto, MOLERO MARAÑ́́N, $\mathrm{M}^{\mathrm{a}}$. Luisa, "Las trabajadoras del cuidado: por un futuro de trabajo decente", Revista de Derecho Social, no. 89, 2020, pp. 33-36.

${ }^{115}$ Informe de Progreso 2020. Reconstruir lo común. 3.2. Derecho a cuidar y ser cuidados en condiciones de dignidad.

https://www.agenda2030.gob.es/recursos/docs/Informe de Progreso_2020_Reconstruir_lo_Comun_pdf

${ }^{116}$ En este sentido, resulta muy reveladora STSJ de Canarias, de 20 de enero de 2020; rec. 850/2018; en la misma línea STJUE de 19 de diciembre de 2019, C-450/2018, WA versus INSS. Sobre el complemento de maternidad en las prestaciones de Seguridad Social y su discriminación por razón de sexo al omitirse una cláusula de salvaguarda para los padres que se ocupen del cuidado de los descendientes. Comentario al respecto del primer pronunciamiento, VICENTE PALACIO, Ma ${ }^{\mathrm{a}}$ Aranzazu, "Sobre el carácter discriminatorio del complemento por maternidad (de nuevo sobre la diferencia entre sexo y género), Revista $\begin{array}{lllll}\text { de Jurisprudencia } & \text { Laboral, } & \mathrm{n}^{\circ} . & 4, & 2020 .\end{array}$ https://www.boe.es/biblioteca_juridica/anuarios_derecho/abrir_pdf.php?id=ANU-L-2020-00000000953
} 
La pandemia ha mostrado el efecto de los recortes en las estructuras de atención social y ha afectado enormemente a las casi inexistentes -y muchas veces informales- estructuras de cuidado y de conciliación. La crisis de los cuidados ya estaba presente en nuestra realidad social, pero la pandemia ha visibilizado con contundencia su precariedad y necesidad de que sea abordada con urgencia y de forma comprehensiva. En el contexto de la actual pandemia, más allá de los permisos recuperables, parece acertada la propuesta de que se reconozca una modalidad concreta de prestación de carácter asistencial para aquellas personas trabajadoras cuya adaptación del puesto devenga imposible y tengan que hacerse cargo de familiares o menores enfermos de coronavirus o en situación de aislamiento por riesgo de contagio ${ }^{117}$.

Por tanto, además de promover la corresponsabilidad en el interior de las familias, es necesario que el Estado se haga corresponsable, lo que implica necesariamente articular una red pública de cuidados que sostenga desde lo común una parte importante de esas tareas, con salarios y empleos de calidad, y con todas las garantías para quienes cuidan y son cuidados. Sin duda será un paso más que hace mucho que viene reclamándose, en la interminable senda hacia "la realidad de la igualdad sustancial de los seres humanos y la necesidad de su continua actualización en busca de su plenitud en una sociedad democrática" $" 118$.

\section{Bibliografía}

ALEMÁN PÁEZ, Francico, "El derecho a la desconexión digital. Una aproximación conceptual, crítica y contextualizada al hilo de la 'Loi Travail n'. 2016-1088', Revista Trabajo y Derecho, n'. 30, 2017.

ARANGÜREZ VALENZUELA, Lucía, "El impacto de las tecnologías de la información y de la comunicación en el tiempo de trabajo: una especial referencia a la desconexión digital”, en AA. VV., La adaptación del ordenamiento español a la jurisprudencia social del Tribunal de Justicia, Cinca, Madrid, 2018.

BALLESTER PASTOR, Ma . Amparo, "De los permisos parentales a la conciliación: Expectativas creadas por la Directiva 2019/1158 y su transposición al ordenamiento español”, Revista de Derecho a las Relaciones Laborales, $\mathrm{n}^{\circ}$. 11, diciembre 2019.

BARRIOS BAUDOR, Guillermo L., "Adaptaciones y/o reducciones especiales de jornada con ocasión de la crisis sanitaria COVID-19: Plan MECUIDA”, Revista Aranzadi Doctrinal, nº 6, 2020 (BIB 2020\12109).

\footnotetext{
117 A modo de una prestación similar a la del art. 190 LGSS para el cuidado de menores afectados por cáncer u otra enfermedad grave, GOERLICH PESET, José $\mathrm{M}^{\mathrm{a}}$., "Vuelta al 'cole' en el contexto de la Covid19: problemas de conciliación de la vida laboral $\mathrm{y}$ familiar", Blog. Foro de Labos, https://forodelabos.blogspot.com/2020/09/vuelta-al-cole-en-el-contexto-de-la.html

${ }^{118}$ Excepcional estudio sobre la igualdad en el empleo entre hombres y mujeres, CASAS BAAMONDE, $M^{a}$. Emilia, "La igualdad de género en el Estado constitucional”, Revista de Derecho Social, nº. 88, 2020, p. 17.
} 
BAYLOS GRAU, Antonio, "Una nota sobre el papel de la negociación colectiva en la configuración de los derechos derivados de la Ley Protección de datos Personales y garantías de los derechos digitales”, Revista de Derecho Social-editorial-, nº 84, 2019.

BITTMAN Michael y FOLBRE, Nancy., Family time. The social organization of care, Ed. Routledge, London-New Yok, 2004.

BLASCO JOVER, Carolina, "Tres preguntas (con respuesta) sobre la excedencia por cuidado de hijos: cuando se requiere reformar la norma para ampliar su protección", Revista de Derecho Social, no 86.

BLASCO PELliCER, Ángel, LÓPEZ BALAGUER, Mercedes, ALEGRE NUENO, Manuel, RAMOS MORAGUES, Francisco, TALÉNS VISCONTI, Eduardo, Análisis normativo de las medidas laborales y de seguridad social frente a la crisis del COVID19", Tirant lo Blanch, Valencia, 2020.

CABEZA PEREIRO, Jaime, El trabajo a tiempo parcial y las debilidades del modelo español, Bomarzo, Albacete, 2013.

CARACCIOLO DI TORELLA, Eugenia y MASSELOT Annik, Reconciling Work and Family Life in EU Law and Policy, Palgrave- Macmillan, London, 2010.

CASAS BAAMONDE, Ma . Emilia y RODRÍGUEZ-PIÑERO Y BRAVO FERRER, Miguel, "Un nuevo Derecho del Trabajo en la emergencia. Las medidas laborales y de seguridad social excepcionales en el estado de alarma declarado por la crisis sanitaria de Covid-19”, Derecho de las relaciones laborales, $\mathrm{n}^{\circ}$. 4, 2020.

CASAS BAAMONDE, Ma . Emilia, "La organización del tiempo de trabajo con perspectiva de género: ña conciliación de la vida privada y la vida laboral", Documentación Laboral, ${ }^{\circ}$. 117, 2019.

CASAS BAAMONDE, Ma. Emilia, "La igualdad de género en el Estado constitucional", Revista de Derecho Social, $\mathrm{n}^{\circ} .88,2020$.

CIALTI, Pierre H., "El derecho a la desconexión en Francia: ¿más allá de lo que parece?”, Temas Laborales, $\mathrm{n}^{\circ}$. 137, 2017.

COUNTOURIS, Nicola, DE STEFANO, Valerio, EWING, Keith, y FREEDLAND, Mark, "Covid-19 crisis makes clear a new concept of 'worker' is overdue", Social Europe, vol. 2, 2020.

CRUZ VILLALÓN, Jesús, "Del coranavirus al contagio del teletrabajo", en Nueva Tribuna, 21 de marzo 2020.

FERNÁNDEZ NIETO, Livina A., "El teletrabajo: de actor secundario a protagonista en el escenario del COVID-19”, Diario La Ley, n. 9703, 24 de septiembre de 2020.

FERNÁNDEZ PROL, Francisca, "Relaciones de trabajo ante el proceso de digitalización de una economía: análisis desde una óptica de género", Revista de Derecho Social, nº. $89,2020$. 
FERRADANS CARAMÉS, Carmen, "Impacto de la doctrina del Tribunal de Justicia de la Unión Europea sobre la aplicación del principio de igualdad y no discriminación a los trabajadores a tiempo parcial", Tutela y promoción de la plena integración de la mujer en el trabajo. Libro homenaje a la profesora Teresa Pérez del Río, CRUZ VILLALÓN, Jesús, GARRIDO PÉREZ, Eva y FERRADANS CARAMÉS, Carmen (coords.), Consejo Andaluz de Relaciones Laborales, 2015.

GALA DURÁN, Carolina, "La nueva forma de cálculo de la pensión de jubilación de los trabajadores a tiempo parcial: Comentario a la STJUE de 8 de mayo de 2019 (asunto Villar Láiz) y a la STC 91/2019, de 3 de julio", La administración práctica: enciclopedia de administración municipal, $\mathrm{n}^{\circ} 10,2019$.

LÓPEZ BALAGUER, Mercedes, "El derecho de adaptación de jornada y de modificación de la prestación”, en AA. VV., Los derechos de conciliación en la empresa. Actualizado al RDLey 6/2019, de 1 de marzo, de medidas urgentes para garantía de la igualdad de trato y de oportunidades entre mujeres y hombres en el empleo y la ocupación, Tirant lo Blanch, Valencia, 2019.

LÓPEZ BALAGUER, Mercedes, "Los derechos de conciliación en la crisis del Covid19”, El Derecho, n'. 2, junio, 2020.

LOUSADA AROCHENA, Fernando y RON LATAS, Ricardo, "El permiso para el cuidado del lactante y la nueva prestación por su ejercicio corresponsable", Revista de Derecho Social y de Empresa, nº. 12, 2020.

MARTÍNEZ MORENO, Carolina, "La nueva regulación de la adaptación de la jornada con fines de conciliación. ¿Hasta dónde llega el avance?”, Revista Derecho Social y de Empresa, $\mathrm{n}^{\mathrm{o}} .12,2020$.

MELLA MENDEZ, Lourdes, "Mujer trabajadora y empleo tecnológico: medidas de actuación urgente contra la brecha digital de género", Trabajo y Derecho, nº. 66, 2020.

MIÑARRO YANINI, Margarita, "Impacto del Reglamento de Protección de Datos en las relaciones laborales: un -pretendido- cambio cultural", CEF. Revista de Trabajo y Seguridad Social, nº . 423, 2018.

MOLERO MARAÑÓN, Ma . Luisa, "Las trabajadoras del cuidado: por un futuro de trabajo decente", Revista de Derecho Social, n. 89, 2020.

MOLINA NAVARRETE, Cristóbal, "Jornada laboral y tecnologías de la infocomunicación: 'la desconexión digital', garantía del derecho al descanso", Temas Laborales, $\mathrm{n}^{\circ} .138,2017$.

NÚÑEZ-CORTÉS CONTRERAS, Pilar, “Avances en corresponsabilidad y flexibilidad en el cuidado del lactante y la adaptación de la jornada por motivos familiares", Revista General de Derecho del Trabajo y de la Seguridad Social, nº. 55, 2020.

PUEBLA DE LA PINILLA, Ana, "El trabajo de las mujeres en la era digital”, Trabajo y Derecho, 2019, $\mathrm{n}^{\circ} .58$. 
RAMOS QUINTANA, Margarita I., "El Pilar Europeo de Derechos Sociales: la nueva dimensión social europea”, Revista de Derecho Social, nº. 77, 2017, pp.19-42.

RODRÍGUEZ PASTOR, Guillermo, "Tiempo de trabajo tras la reforma operada por la LOI”, en AA.VV., Los aspectos laborales de la Ley de Igualdad, Tirant lo Blanch, 2007.

RODRÍGUEZ RODRÍGUEZ, Emma, "El derecho a la negociación colectiva del trabajador autónomo en el contexto de la nueva economía digital", Temas Laborales, $\mathrm{n}^{\circ}$. $151,2020$.

RODRÍGUEZ RODRÍGUEZ, Emma, "La transcendencia de la disponibilidad horaria del trabajador en el contexto de las plataformas digitales", Temas Laborales, $\mathrm{n}^{\circ}$. 146, 2019.

RODRÍGUEZ RODRÍGUEZ, Emma, Instituciones de conciliación de trabajo con el cuidado de familiares, Bomarzo, 2010.

SÁENZ LARA, Carmen, “Algoritmos y discriminación en el empleo: un reto para la normativa antidiscriminatoria", Revista Española de Derecho del Trabajo, $\mathrm{n}^{\circ}$. 232, junio, 2020.

SALA FRANCO, Tomás y BALLESTER PASTOR, Ma . Amparo, Reducción y Adaptación de la jornada por conciliación, Tirant lo Blanch, Valencia, 2009.

SALCEDO BELTRÁN, Carmen, "La Carta Social Europea y la protección de los Derechos Sociales en el marco del Consejo de Europra", en AA.VV., Lecciones sobre Estado Social y Derechos Sociales, Tirant lo Blanch, Valencia, 2014, pp. 154-162.

SALCEDO BELTRÁN, Carmen, "La crítica situación de los derechos sociales de la infancia, de las familias y de los migrantes: Conclusiones 2019 del Comité Europeo de Derechos Sociales", Revista de Derecho de las Relaciones Laborales, $\mathrm{n}^{\circ}$. 6, junio 2020, pp. 900-917.

TALÉNS VISCOTI, Eduardo, "La desconexión digital en el ámbito laboral: un deber empresarial y una nueva oportunidad de cambio para la negociación colectiva", Revista de Información Laboral, $\mathrm{n}^{\circ}$. 4, 2018.

USHAKOVA, Tatsiana, "De la conciliación a la desconexión tecnológica. Apuntes para el debate", Revista Española de Derecho del Trabajo, n. 192, 2016, parte Estudios (BIB 2016/85593).

VICENTE PALACIO, Ma. Aranzazu, "Sobre el carácter discriminatorio del complemento por maternidad (de nuevo sobre la diferencia entre sexo y género), Revista de Jurisprudencia Laboral, $\mathrm{n}^{\circ}$. 4, 2020.

\section{ANEXO}

BAYLOS GRAU, Antonio, "Una nota sobre el papel de la negociación colectiva en la configuración de los derechos derivados de la Ley Protección de datos Personales y garantías de los derechos digitales", http://baylos.blogspot.com/2018/11/la-garantia-de$\underline{\text { los-derechos-digitales.html }}$ 
BELTRÁN HEREDIA, Ignasi, "Breves notas. ¿Qué normas deben aplicarse al trabajo a distancia adaptado en el marco del COVID-19" https://ignasibeltran.com/2020/10/05/breves-notas-que-normas-deben-aplicarse-altrabajo-a-distancia-adoptado-en-el-marco-del-covid19-tras-el-rdley-28-2020/

BELTRÁN HEREDIA, Ignasi, “COVID-19 y ERTE por fuerza mayor y situaciones que lo justifican" https://ignasibeltran.com/2020/03/27/covid-19-y-erte-por-fuerza-mayorsituaciones-que-lo-justifican-y-acreditacion/.

BELTRÁN HEREDIA, Ignasi, "Tiempo de trabajo y descanso"https://ignasibeltran.com/tiempo-de-trabajo-y-

descanso/\#solicitudadaptaci\%C3\%B3n

CRUZ VILLALÓN, Jesús, "Del coranavirus al contagio del teletrabajo",https://www.nuevatribuna.es/articulo/actualidad/coronavirusconfinamiento-teletrabajo-covid19-oms-salud/20200320232306172385.html

GOERLICH PESET, José M", "Vuelta al 'cole' en el contexto de la Covid-19: problemas de conciliación de la vida laboral y familiar", Blog. Foro de Labos, https://forodelabos.blogspot.com/2020/09/vuelta-al-cole-en-el-contexto-de-la.html

LÓPEZ BALAGER, Mercedes, "La voluntariedad del trabajo a distancia en el RDL 28/2020: ¿es el derecho al trabajo a distancia por conciliación una excepción?, Blog. Foro de Labos, https://forodelabos.blogspot.com/2020/10/la-voluntariedad-del-trabajodistancia.html

POZZAN, Emmanuela y CATTANEO, Umberto "Trabajadoras sanitarias: Trabajo sin descanso en hospitales $y$ en el hogar", https://www.ilo.org/global/about-theilo/newsroom/news/WCMS_741192/lang--es/index.htm

ROJO TORRECILLA, Eduardo, "Los derechos digitales laborales en la Ley Orgánica 3/2018, de 5 de diciembre, de Protección de datos Personales y garantías de los derechos digitales. Notas al título X", http://www.eduardorojotorrecilla.es/2018/12/los-derechosdigitales-laborales-en-la.html

ROJO TORRECILLA, Eduardo, "Semestre europeo: prioridades económicas". http://www.eduardorojotorrecilla.es/2020/03/semestre-europeo-prioridades economicas.html

TALENS VISCONTI, Eduardo en el blog. "Foro Labos", "El decálogo de novedades El decálogo de novedades introducidas por el RDL 13/2020, de 7 de abril, en relación con la prestación extraordinaria por cese de actividad de los trabajadores autónomos https://forodelabos.blogspot.com/2020/04/el-decalogo-de-novedades-introducidas.html

TRILLO PÁRRAGA, Francisco “¿Qué está cambiando en el derecho del trabajo con la crisis del covid-19? una reflexión de francisco trillo" el blog. del Prof. BAYLOS GRAU, A., https://baylos.blogspot.com/2020/04/que-esta-cambiando-en-el-derecho-del.html 